\title{
Off-fault tensile cracks: A link between geological fault observations, lab experiments, and dynamic rupture models
}

\author{
D. Ngo, ${ }^{1}$ Y. Huang, ${ }^{2}$ A. Rosakis, ${ }^{1}$ W. A. Griffith, ${ }^{3}$ and D. Pollard ${ }^{4}$ \\ Received 10 June 2011; revised 4 November 2011; accepted 16 November 2011; published 20 January 2012.
}

[1] We examine the local nature of the dynamic stress field in the vicinity of the tip of a semi-infinite sub-Rayleigh (slower than the Rayleigh wave speed, $c_{R}$ ) mode II crack with a velocity-weakening cohesive zone. We constrain the model using results from dynamic photoelastic experiments, in which shear ruptures were nucleated spontaneously in Homalite-100 plates along a bonded, precut, and inclined interface subject to a far-field uniaxial prestress. During the experiments, tensile cracks grew periodically along one side of the shear rupture interface at a roughly constant angle relative to the shear rupture interface. The occurrence and inclination of the tensile cracks are explained by our analytical model. With slight modifications, the model can be scaled to natural faults, providing diagnostic criteria for interpreting velocity, directivity, and static prestress state associated with past earthquakes on exhumed faults. Indirectly, this method also allows one to constrain the velocity-weakening nature of natural ruptures, providing an important link between field geology, laboratory experiments, and seismology.

Citation: Ngo, D., Y. Huang, A. Rosakis, W. A. Griffith, and D. Pollard (2012), Off-fault tensile cracks: A link between geological fault observations, lab experiments, and dynamic rupture models, J. Geophys. Res., 117, B01307, doi:10.1029/ 2011 JB008577.

\section{Introduction}

[2] Cracks in nominally elastic materials have long been understood to carry huge stress concentrations at their tips [e.g., Inglis, 1913; Griffith, 1925; Orowan, 1949; Yoffe, 1951]. In the Earth sciences, crack tip stress concentrations are responsible for processes related to growth of and deformation around geological structures, including faults, joints, veins, deformation bands, solution surfaces, and sheet intrusions [e.g., Pollard and Segall, 1987]. Earthquake ruptures are frequently idealized as moving mode II (shear) cracks which propagate along a preexisting plane of weakness (a fault). As can be seen from the elastodynamic asymptotic solution [Freund, 1990] for moving mode II cracks, the maximum principal stress amplitude in the vicinity of the tip is influenced by the velocity at which the crack is propagating: the faster the rupture speed, the larger the amplitude of the principal stresses. As the velocity of the propagating mode II rupture tip $\left(v_{\mathrm{II}}\right)$ approaches the Rayleigh wave speed $\left(c_{R}\right)$, the tensile principal stress can reach values large enough to significantly exceed the strength of

\footnotetext{
${ }^{1}$ Graduate Aerospace Laboratories, California Institute of Technology, Pasadena, California, USA.

${ }^{2}$ Department of Mechanical Engineering and Department of Civil and Environmental Engineering, Northwestern University, Evanston, Illinois, USA.

${ }^{3}$ Department of Geology and Environmental Science, University of Akron, Akron, Ohio, USA.

${ }^{4}$ Department of Geological and Environmental Sciences, Stanford University, Stanford, California, USA.
}

Copyright 2012 by the American Geophysical Union. 0148-0227/12/2011JB008577 the rocks surrounding the fault resulting in inelastic deformation [e.g., Poliakov et al., 2002; Samudrala et al., 2002; Rice et al., 2005]. At shallower depths such dynamic stress amplifications also have been shown to lead to pulverization [e.g., Reches and Dewers, 2005; Yuan et al., 2011], although evidence from seismology, geodesy, and theory suggests that pulverization and extensive off-fault failure is thought to extend only above $\sim 5 \mathrm{~km}$ depth due to increasing static confining pressure in the far field, which combats extensive failure in tension [Li et al., 1994; Ben-Zion et al., 2003; Fialko, 2004; Ben-Zion and Shi, 2005]. At greater depths, damage due to dynamic tensile fracturing is expected to be less extensive [e.g., Ben-Zion and Shi, 2005]; however, damage localized around faults exhumed from seismogenic depths has been reported [e.g., Martel et al., 1988; Martel and Pollard, 1989; Martel, 1990; Griffith et al., 2009c, 2010].

[3] Field evidence of supershear earthquakes [e.g., Archuleta, 1984; Olsen et al., 1997; Bouchon et al., 2001; Bouchon and Vallée, 2003; Bhat et al., 2007] and laboratory observations of shear ruptures propagating near $c_{R}$ or even exceeding the elastic shear wave speed $\left(c_{\mathrm{s}}\right)$ [Rosakis et al., 1999; Rosakis, 2002; Xia et al., 2004; Rosakis et al., 2007] underscore the need for considering high $v_{\mathrm{II}}$, and fault rupture dynamics in the mechanical picture of rupture propagation and termination. The theoretical maximum speed for $v_{\text {II }}$ in a homogeneous material is $c_{\mathrm{R}}$; however, rupture speeds faster than $c_{s}$ and approaching the longitudinal wave speed $\left(c_{1}\right)$ are theoretically permissible along straight, previously established planes of weakness [Andrews, 1976; Freund, 1979; Broberg, 1995; Rosakis, 2002]. The observation of 

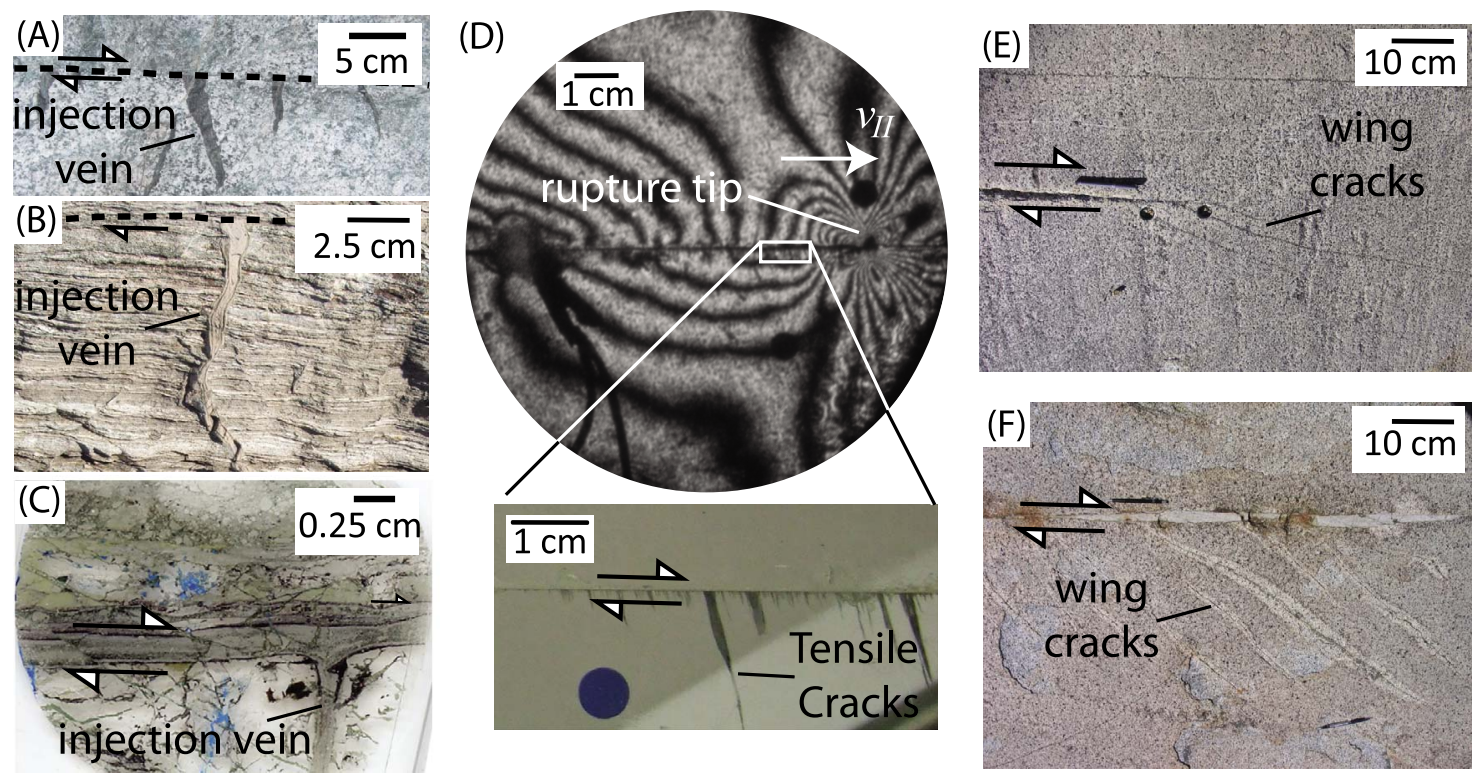

Figure 1. Comparison of tensile cracks formed in various loading conditions in nature and the laboratory. $(\mathrm{a}-\mathrm{c})$ Pseudotachylye veins of dynamic origin from the Adamello batholiths [e.g., Di Toro et al., 2005a], the Fort Foster Brittle Zone [e.g., Swanson, 1988], and the Mt. Abbot Quadrangle of the Sierra Nevada [e.g., Griffith et al., 2008], respectively. (d) Fringe patterns surrounding a propagating shear rupture in Homalite-100 and resulting tensile cracks inclined at a steep angle to the rupture interface. (e and f) Examples of wing cracks at static fault tips from the Mt. Abbott Quadrangle [e.g., Mutlu and Pollard, 2008].

fast rupture velocities during natural earthquakes and wellcontrolled laboratory experiments coupled with a strong velocity dependence of the stress field surrounding a rapidly propagating rupture tip has obvious implications for geologists analyzing exhumed faults: fault structures that previously were elusive within the context of quasi-static fault mechanics may be explainable with the additional consideration of rupture velocity [e.g., Sagy et al., 2001, 2002; Samudrala et al., 2002; Reches and Dewers, 2005; Di Toro et al., 2005a; Griffith et al., 2009b].

[4] Several theoretical studies have explored the generation of off-fault brittle deformation related to propagating earthquake ruptures. Yamashita [2000] studied numerically the formation of tensile crack populations around propagating ruptures and their effects on seismic radiation and rupture propagation. Samudrala et al. [2002] explained the occurrence of secondary microcracks in experiments by Rosakis et al. [1999], featuring intersonic $\left(v_{\mathrm{II}}>c_{\mathrm{S}}\right)$ ruptures growing along a straight cohesive interface in Homalite- 100. They used an analytical solution for a semi-infinite mode II rupture with a velocity-weakening cohesive zone propagating at a constant, intersonic velocity. Poliakov et al. [2002] studied 2-D semi-infinite sub-Rayleigh (slower than the Rayleigh wave speed, $c_{R}$ ) mode II ruptures with a slipweakening tip zone to examine the influence of the prestress state and rupture velocity on the preference of earthquake ruptures to remain on a straight path or to follow intersecting faults at different orientations to the primary fault. They found that the prestress state strongly influenced the potential for ruptures to follow bend paths, while increasing rupture velocity increases the extent of the influence of the near tip stress field, implying likewise a larger zone of potential damage. Rice et al. [2005] extended this analysis for pulselike ruptures in poroelastic media. While Biegel et al.
[2007], Sammis et al. [2009], and Biegel et al. [2010] performed experiments to study the interaction of dynamically growing ruptures with off-fault fracture populations, Dalguer et al. [2003] used the discrete element method to study tensile crack growth along 3-D strike-slip ruptures and found that tensile crack populations grew toward the free surface in configurations resembling "flower structures" which are common at shallow depths along crustal-scale strike-slip faults. Bhat et al. [2007] studied off-fault stressing due to a self-healing slip-weakening slip pulse propagating at supershear velocities and found that such a rupture could induce Coulomb failure at significant distances from the rupture. This observation was used to explain otherwise anomalous surface cracking found several kilometers from the rupture traces [Xu et al., 2006; Bhat et al., 2007]. Of these studies, only the theoretical investigations of Samudrala et al. [2002] were compared to experimental generation of cracks around dynamic ruptures.

[5] Despite the theoretical and experimental realization of the effect of crack growth dynamics on off-fault damage creation, only a few field observations of cracking related to passing earthquake ruptures have been reported. Di Toro et al. [2005a] suggested the importance of considering these dynamic fields by pointing out that pseudotachylyte injection veins along exhumed faults in the Adamello batholith in the Northern Italian Alps are commonly nearly orthogonal to the main fault surface and occur preferentially on one side of the fault surface (e.g., Figure 1), and showed that these observations may be explained in terms of the dynamic stress fields due to mode II rupture tips propagating at fast sub-Raleigh velocities. Indeed, the orientation and distribution of these injection veins show they bear striking similarities to tensile cracks formed adjacent to experimentally produced ruptures (Figures $1 \mathrm{a}-1 \mathrm{~d}$ ). 


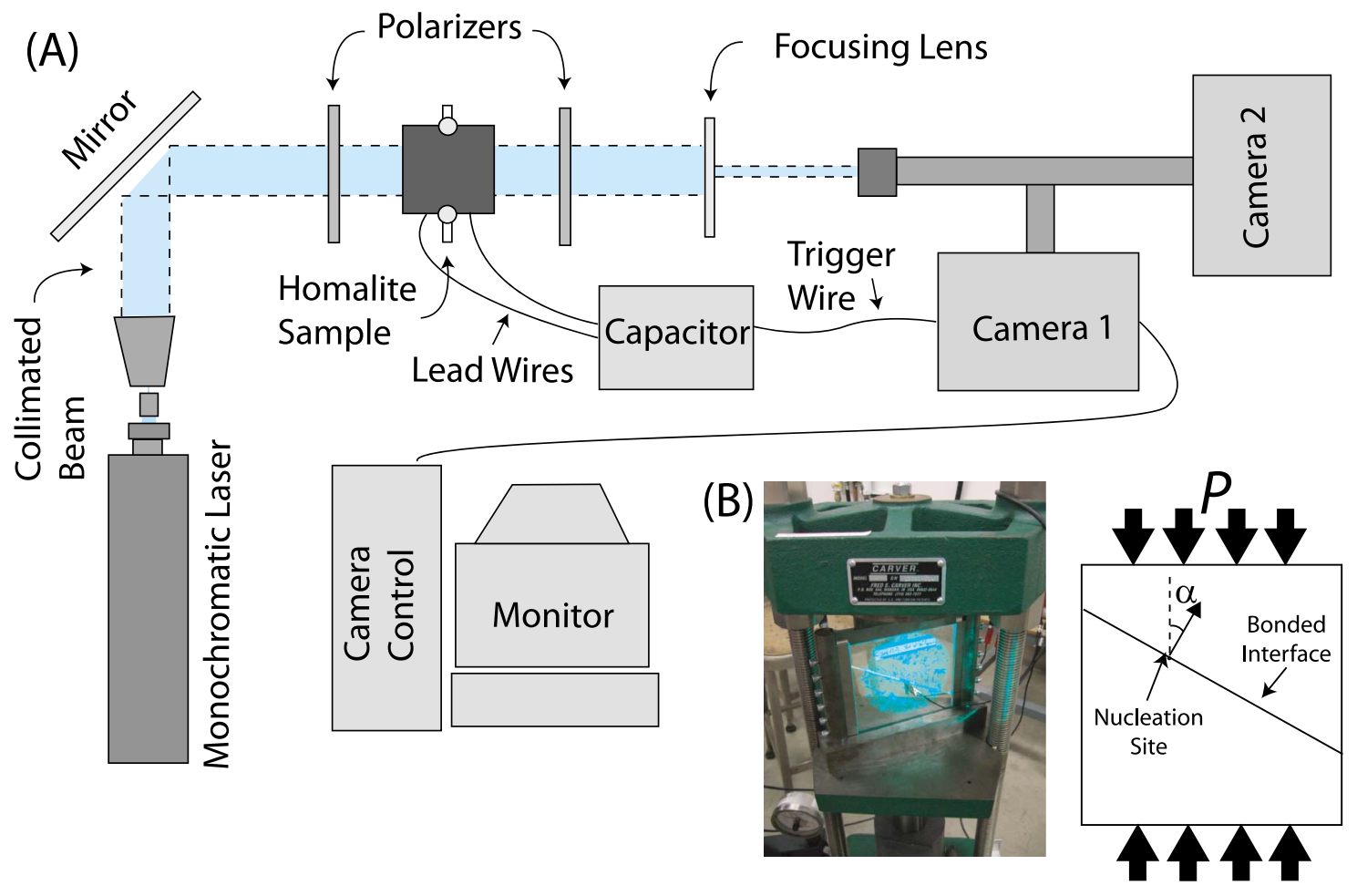

Figure 2. (a) Photoelastic apparatus including laser light source, polarizing filters, and high-speed cameras. (b) Hydraulic press and sample configuration showing the relative orientation of the vertical load $(P)$ and inclination of the interface $(\alpha)$. Explosion induces a bilateral right-lateral shear rupture upon explosion.

[6] Motivated by the observations of Samudrala et al. [2002] and Di Toro et al. [2005a], Griffith et al. [2009b] investigated sub-Rayleigh shear ruptures in Homalite-100 plates along a bonded precut interface inclined at an angle $\alpha$ and subject to a far-field uniaxial stress $P$ (Figure 2). This far-field stress mimics the static prestress acting on faults in the Earth's crust; therefore, the experimental configuration of Griffith et al. [2009b] is a closer representation of natural earthquake ruptures than the experiments of Samudrala et al. [2002]. The experimental shear rupture events produced damage zones, consisting of an array of tensile cracks (Figure 1d) that nucleated and grew dynamically within the tip zone of the shear ruptures, which were propagating along the bonded frictional interface (laboratory fault). The cracks formed only on one side of the laboratory fault, which is consistent with the asymmetric nature of the normal stress distribution around mode II crack tips. In addition, the orientation of the tensile cracks appeared to be strongly related to the shear rupture velocity and the static prestress state [Griffith et al., 2009b].

[7] Here we develop an analytical steady state dynamic shear crack model with a velocity-weakening cohesive zone to elucidate the physics of the propagating rupture tip responsible for the stress perturbation associated with the observed tensile crack growth in the experiments on Homalite- 100.

[8] The primary objective of this study is to explain the occurrence and inclination of the tensile (mode I) cracks which developed during the experiments of Griffith et al. [2009b]. Modifications are subsequently made to the resulting, laboratory-calibrated, analytical model allowing us to scale our observations of dynamic tensile cracking in the laboratory setting to natural faults exhumed from seismogenic $(5-15 \mathrm{~km})$ depths. Results of this scaling suggest that conditions of rupture velocity and static prestress state of ancient ruptures can be very tightly constrained by examining the inclination angle of tensile cracks distributed along exhumed faults.

\section{Experiments and Field Observations}

[9] For subsequent discussions, we differentiate between tensile cracks that grow in response to "dynamic" and "static" loading, as there is currently little distinction in the geologic literature. For brevity, we will heretofore refer to cracks distinguished by loading conditions as "dynamic" and "static" tensile cracks, respectively. Di Toro et al. [2005a] provided strong field evidence that "dynamic" tensile cracks containing pseudoatachylyte (pseudotachylyte injection veins) might form as a result of a transient stress perturbation due to a passing earthquake rupture. Pseudotachylyte injection veins along exhumed faults in the Adamello batholith in the Northern Italian Alps occur quasiperiodically and dominantly on one side of the fault and are nearly orthogonal to the main fault surface. Such high-angle veins are also common along other pseudotachylyte bearing faults (Figures 1b and 1c) [Swanson, 1988; Griffith et al., 2008], and differ from "static" wing cracks commonly observed near the tips of faults, which are related to the quasi-static perturbed stress field introduced by slip 
(Figures 1e and 1f) [Willemse and Pollard, 1998; Mutlu and Pollard, 2008]. Wing cracks are typically concentrated at the tips of faults, whereas dynamic tensile cracks occur preferentially on one side of the fault and may occur along the length of the fault. Static tensile cracks may also form along nonplanar faults due to stress perturbations at fault bends [Griffith et al., 2010], although such cracks are usually developed on both sides of the fault surface. In addition, static cracks which develop around fault bends along faults exhumed from seismogenic depths may occur centimeters to meters from the fault surface, depending on the roughness amplitude of the fault, whereas dynamic tensile cracks tend to occur within several $\mathrm{cm}$ of the fault, frequently nucleating on the fault surface [Griffith et al., 2010].

[10] In order to test the hypothesis that dynamic tensile cracks might reveal information about the source parameters of ancient ruptures, Griffith et al. [2009b] investigated subRayleigh shear ruptures in Homalite-100 plates along a glued precut interface inclined at an angle $\alpha$ and subject to a far-field uniaxial stress $P$ (Figure 2). Transient stress fields during the experiments were recorded using dynamic photoelasticity [Kavaturu et al., 1998] and high-speed digital photography [e.g., Rosakis, 2002], yielding patterns of isochromatic fringes (Figure 1d) that are contours of maximum in-plane shear stress. Shear rupture experiments were conducted under a variety of prestress states with inclination angles of $\alpha=60^{\circ}, 70^{\circ}$, and $80^{\circ}$. Within each experiment, $v_{\mathrm{II}}$ varied smoothly within $\sim 10 \%$ of $c_{\mathrm{s}}$ for Homalite-100, yet the inclination angle $\theta$ of dynamic tensile cracks formed during the experiments was sensitive even to such small changes in velocity (Figure 3). Arrays of tensile microcracks were produced during shear rupture in all experiments at $\alpha=60^{\circ}$ and $70^{\circ}$ (Figures 1 and 3), but microcracks were not observed at $\alpha=80^{\circ}$. The tensile cracks nucleated and grew dynamically within the cohesive zone behind the tip of the shear rupture as it propagated along the bonded frictional interface [Griffith et al., 2009b]. The cracks were interpreted to be pure tensile (mode I) cracks due to the presence of symmetrical shadow spots at the propagating crack tips [Rosakis et al., 2000; Griffith et al., 2009b]. The tensile cracks were produced only on one side of the rupture interface, where transient, fault-parallel, tensile stress perturbations were associated with the growing shear rupture tip. For greater values of $\alpha$, the remote compressive stress $P$ resolves lesser normal and shear tractions on the interface and greater compression parallel to the interface which inhibits tensile cracking. In all cases, microcracks formed at high angles to the rupture interface, and longer cracks curved slightly as they propagated into the Homalite specimen. Microcrack length and spacing also varied systematically with velocity of the main rupture and the prestress state; however, we focus on microcrack orientation in this paper. It is worth emphasizing that the laboratory experiments of Griffith et al. [2009b], only produced off-fault tensile failure. Dynamic shear crack growth (shear failure) in monolithic brittle solids in the absence of interfaces has never been observed in a laboratory setting. Indeed when cracks are generated in the bulk material adjacent to a main fault, these grow in the direction which promotes opening and to our knowledge are never seen to propagate as a shear ruptures in the absence of additional weak interfaces. Laboratory investigation of off- fault shear failure would require the introduction of additional flaws or weak interfaces within the Homalite material.

[11] The experiments described by Griffith et al. [2009b] were conducted along an interface with cohesive and frictional strength, which differentiates them from previous experiments in which arrays of tensile cracks were formed during shear rupture along a precut interface [Rosakis et al., 1999, 2000]. In these previous experiments, tensile microcracks were produced by shear ruptures induced by projectile impact on a cohesive (i.e., bonded) interface which was weak with respect to the host Homalite material [Rosakis et al., 1999]. This cohesive interface had little frictional strength, as it was not subject to any remote loading. More recently, subshear and supershear bilateral ruptures have been produced in the laboratory which more closely simulate geologic conditions of faulting in that they were subjected to remote uniaxial loading and frictional strength [e.g., Xia et al., 2004, 2005; Rosakis et al., 2007]. In these experiments ruptures occur along a frictional (but cohesionless) interface, and the rupture was induced by an exploding wire embedded within the Homalite adjacent to the interface. However, secondary microcracks like those observed by Rosakis et al. [1999, 2000] and analyzed by Samudrala et al. [2002] were not observed in any of these experiments. Samudrala et al. [2002] and Poliakov et al. [2002] show that the off-fault stress concentration due to a propagating shear rupture is related to the rupture velocity $v_{I I}$ and to the peak shear traction $\tau_{p}$ attained along the rupture surface (i.e., shear stress needed to overcome the total interface strength). In the previous laboratory studies, this total interface strength $\tau_{0}$ was either due to quasi-static cohesive strength, $\tau_{c}$, of the glued bond [Rosakis et al., 1999, 2000; Samudrala et al., 2002], or to frictional strength $\tau_{f}$ of the interface due to the remote compressive stress P [Xia et al., 2004, 2005; Lu et al., 2007; Rosakis et al., 2007]. Because cracks have not been observed to form in the latter frictional configuration, Griffith et al. [2009b] applied the adhesive bond to the interface, resulting in a strengthening of the interface by the amount $\tau_{c}$. Therefore, the total static interface strength is $\tau_{0}=\tau_{c}+\tau_{f}$. Here $\tau_{f}=f_{s} \sigma_{n}$, where $f_{s}$ is the static friction coefficient, and $\sigma_{n}$ is the normal traction resolved on the interface. Note the important difference in symbols used to describe the cohesive, frictional, and total interface strength between Griffith et al. [2009b] and the current paper. Because the propagating rupture must overcome both $\tau_{f}$ and $\tau_{c}$ this results in a magnification of the off-fault normal stress components, encouraging tensile failure of the Homalite. The fact that both friction and cohesion were necessary to generate tensile cracks in the experiments of Griffith et al. [2009b] suggests that dynamic tensile cracking along faults during earthquakes may occur preferentially along strong faults which have some cohesive strength, and their formation is strongly dependent on the static prestress state present at the time of the earthquake rupture.

[12] It is worth noting that for the parameter $\left(f_{\mathrm{s}}=0.32\right)$ determined by Griffith et al. [2009b] for the bonded interface, optimal angle between the rupture plane and the maximum compressive stress for shear failure is $\sim 36^{\circ}$, corresponding to $\sim \alpha=54^{\circ}$. This explains why the load $P$ was smallest for experiments with $\alpha=60^{\circ}$. However, this parameter space does not correspond to "weak" crustal-scale 

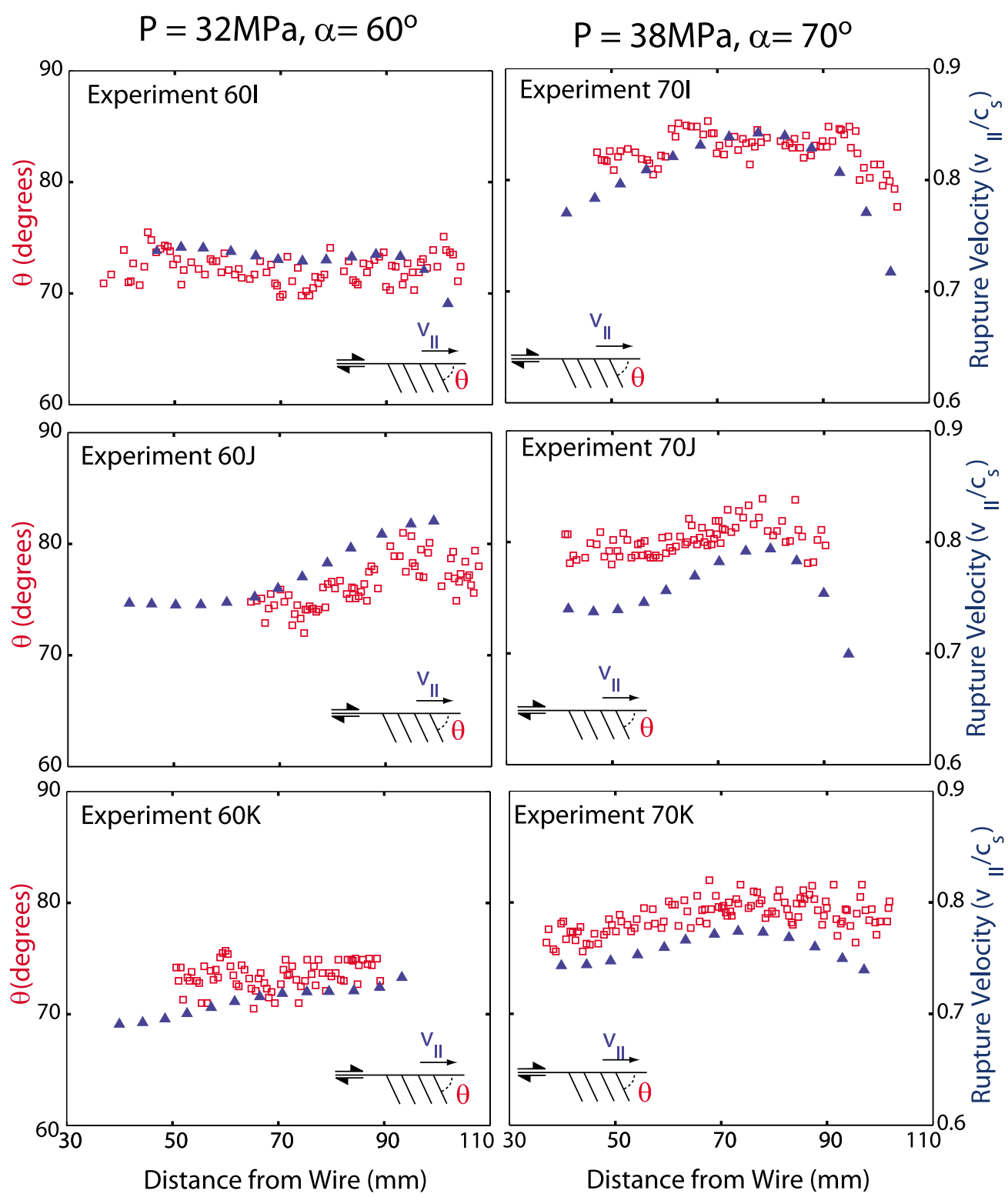

Figure 3. Shear rupture velocity, $v_{I I}$, and microcrack angle, $\theta$, versus distance of rupture tip from the nucleation site for experiments (left) with $P=32 \mathrm{MPa}$ and $\alpha=60^{\circ}$, and (right) with $P=38 \mathrm{MPa}$ and $\alpha=70^{\circ}$. Blue triangles represent the rupture velocity of the main shear rupture, and red squares represent the inclination angle of microcracks.

faults such as the San Andreas fault for which $10^{\circ} \leq \alpha \leq 30^{\circ}$ [e.g., Zoback et al., 1987]. At these angles the critical $P$ for shear failure along the interface is close to or greater than the buckling load for the Homalite specimens. Several experiments were conducted for $\alpha=30^{\circ}$; however, the experiments were unstable, and when ruptures did occur, they almost always propagated at supershear velocities, resulting in very large secondary tensile cracks.

\section{A Velocity-Weakening Model of a Sub-Rayleigh Shear Rupture Growing Along a Fault With Frictional and Cohesive Strength}

[13] The purpose of this section is to determine the local nature of the dynamic stress field in the vicinity of the tip of the shear rupture that is growing along a fault with frictional and cohesive with sub-Rayleigh speed. It is this stress field that is responsible for driving the off-fault mode I microcracks of interest to the present study.

[14] As can be seen in Figure 3, measurable variations of shear rupture speed exist during each of the experiments. However, such variations are gradual and are typically less than $10 \%$ of the shear wave speed of the solid. This observation together with the experimental fact that the off-fault microcracks are generated dynamically in the immediate vicinity of the rupture tip allow us to use a dynamic, "steady state" rupture model in the current section. Indeed, as shown by Freund and Rosakis [1992] for the mode I case and by Liu and Rosakis [1994] for mixed mode, the local near-tip field of a growing rupture always retains its steady state 


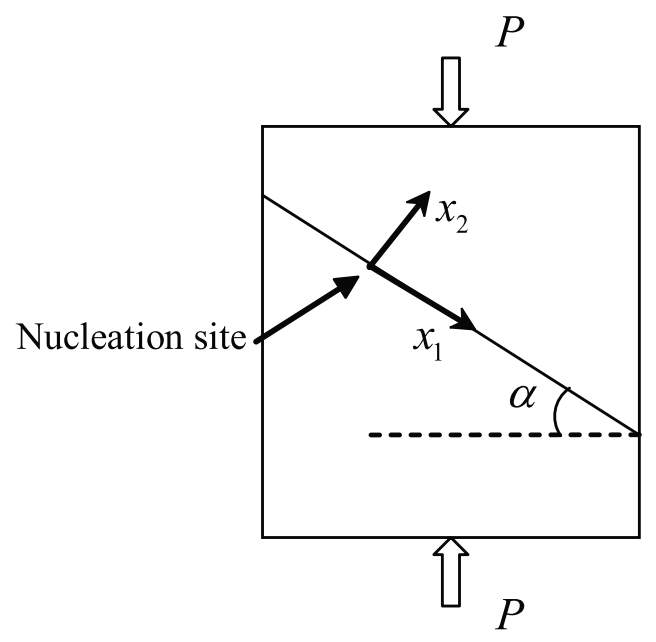

Figure 4. In-plane cross section of specimen and fixed coordinate system $\left(x_{1}, x_{2}\right)$. Origin at the nucleation site and positive $x_{1}$ axis along the fault line.

structure at sufficiently close distances from the rupture front, even if substantial accelerations or decelerations are present.

[15] The additional observation that the microcracks continue to grow for some short time after the rupture tip has passed by, further implies that a model featuring a "distributed" cohesive zone rather than a "point" rupture tip would be necessary to capture the physics of the problem [Rosakis, 2002]. Such distributed cohesive zone models were originally derived to deal with the singular stress concentration associated with linear elastic fracture mechanics which is not physically permissible in materials with finite strength. The major purpose of cohesive zone models is to account for inelastic yielding around the crack tip, thereby avoiding the inherently problematic stress singularity. In the case of dynamic shear rupture, the cohesive zone is a finite length strip zone in which the shear traction acting on the fault decays from a peak value at the leading edge of the rupture to some steady state value at the trailing edge of the rupture. The true decay of shear tractions during frictional sliding is a complex process, as shown by a number experiments on dynamic sliding friction in geomaterials [e.g., Marone, 1998, and references therein]. For the case of fracture mechanics-based dynamic rupture models, this evolution is typically idealized by two end-member classes of models in which the dynamic friction coefficient evolves either with slip (slip-weakening models) or with velocity (velocityweakening models). The former class of models is somewhat more tractable analytically, and has been studied in depth to investigate off-fault secondary shear failure for the case of semi-infinite mode II and mode III shear ruptures by Poliakov et al. [2002] and for the case of dynamic slip pulses by Rice et al. [2005].

[16] The slip-weakening pulse model [Rice et al., 2005] has also been utilized to explain the general orientation and distribution of pseudotachylyte injection veins [Di Toro et al., 2005a]. Di Toro et al. [2005a] concluded based on this formulation that the injection veins formed at the tip of a sub-Rayleigh rupture. Rice and Ruina [1983] proposed that sliding friction is strongly dependent on sliding velocity, and this has been shown to be the case in a variety of experimental settings [e.g., Tsutsumi and Shimamoto, 1997; Di Toro and Pennacchioni, 2004; Yuan and Prakash, 2008]. Numerous studies postulate that earthquake ruptures propagate at speeds approaching the shear wave velocity or faster and slip velocities jump to rates of a few $\mathrm{m} \mathrm{s}^{-1}$ behind the rupture front, and continued slip occurs at about $1 \mathrm{~m} \mathrm{~s}^{-1}$ [Heaton, 1990; Rice, 2006; Tullis et al., 2007]. Based on these observations, we choose to address the somewhat less tractable problem of modeling our experimental results using a velocity-weakening cohesive zone model, with the understanding that qualitatively similar results could also be achieved by utilizing a slip-weakening cohesive zone model. In particular, a sub-Rayleigh modification of the steady state and velocity-weakening shear cohesive zone model by Samudrala et al. [2002] is a viable candidate to adopt for the current study. Our preference in modeling the cohesive and frictional resistance of the interface (fault) by a velocity weakening rather than a slipweakening law (despite its relative complexity) is corroborated by experimental evidence, recently reported by $L u$ et al. [2007] on the basis of similar rupture experiments in Homalite-100. In these experiments, the attainment of both "crack-like" and "pulse-like" shear ruptures in frictional interfaces separating identical Homalie-100 plates provided strong evidence of the activation of a velocity-weakening mechanism during rupture. As described by Zheng and Rice [1998], velocity weakening is the dominant mechanism promoting pulse-like shear ruptures at an interface separating identical solids.

[17] On the basis of the above arguments, we consider a semi-infinite, planar shear rupture (mode II rupture) propagating dynamically along an interface, weak relative to the monolithic host material, separating two identical, homogenous, isotropic, linear elastic solids. In our particular problem, shown in Figure 4, plane stress is the appropriate approximation since the two plates separating the interface are "thin" compared to their in-plane dimensions. The rupture features a zone of length $L$, translating in the front of the rupture tip that resists relative motion due to both friction and cohesion (Figure 5). The rupture tip propagates at a constant, sub-Rayleigh speed $v_{I I}\left(0 \leq v_{I I} \leq \mathrm{c}_{\mathrm{R}}\right)$ in its own plane under either plane strain or plane stress conditions.

[18] An orthonormal coordinate system $\left(0 ; x_{1}, x_{2}, x_{3}\right)$ is placed with its origin at the rupture nucleation site and with the $\left(x_{1}, x_{2}\right)$ plane containing the center plane of the specimen (Figure 4). The positive $x_{1}$ axis lies along the fault line in the direction of rupture growth. The $x_{2}$ axis is perpendicular to the fault and faces toward the upper part of the specimen, while the $x_{3}$ axis points out of the plane of Figure 4 and is not shown.

[19] A detailed view of the rupture tip region, including the fixed coordinate frame, the shear rupture process zone and the shear traction, $\tau$, resisting sliding are shown in Figure 5. In the fixed coordinate system, the in-plane displacement fields $u_{1}$ and $u_{2}$ can be expressed in terms of dilatational and shear displacement potentials $\phi\left(x_{1}, x_{2}, t\right)$ and $\psi\left(x_{1}, x_{2}, t\right)$ as:

$$
\begin{aligned}
& u_{1}\left(x_{1}, x_{2}, t\right)=\frac{\partial}{\partial x_{1}} \phi\left(x_{1}, x_{2}, t\right)+\frac{\partial}{\partial x_{2}} \psi\left(x_{1}, x_{2}, t\right), \\
& u_{2}\left(x_{1}, x_{2}, t\right)=\frac{\partial}{\partial x_{2}} \phi\left(x_{1}, x_{2}, t\right)-\frac{\partial}{\partial x_{1}} \psi\left(x_{1}, x_{2}, t\right) .
\end{aligned}
$$




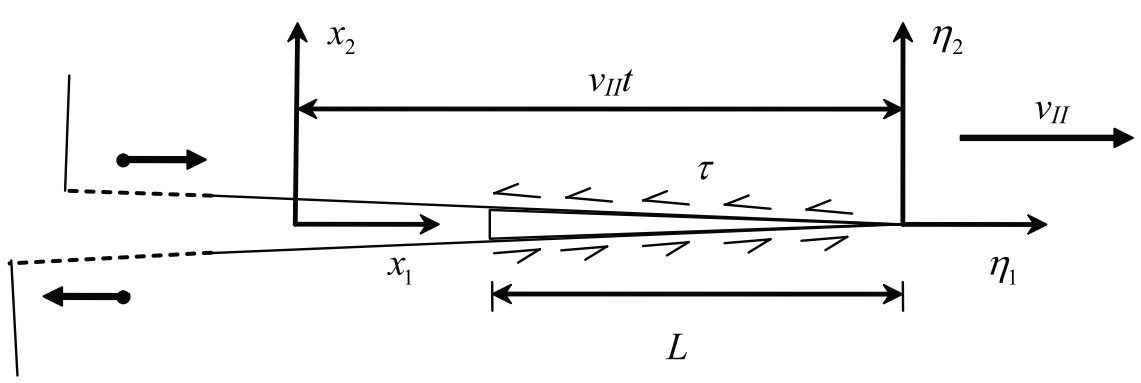

Figure 5. Moving and fixed coordinate systems of the rupture tip and the shear cohesive zone.

These displacements and displacement potentials can also be represented with respect to a moving coordinate system $\left(\eta_{1}, \eta_{2}\right)=\left(x_{1}-v_{I I} t, x_{2}\right)$ centered at the front end of the shear cohesive zone as shown in Figure 5. In this moving coordinate system, the motion of the sub-Rayleigh rupture is governed by two elliptic equations in terms of $\phi$ and $\psi$ as follows:

$$
\begin{aligned}
& \frac{\partial^{2}}{\partial \eta_{1}^{2}} \phi\left(\eta_{1}, \eta_{2}\right)+\frac{1}{\alpha_{l}^{2}} \frac{\partial^{2}}{\partial \eta_{2}^{2}} \phi\left(\eta_{1}, \eta_{2}\right)=0 \\
& \frac{\partial^{2}}{\partial \eta_{1}^{2}} \psi\left(\eta_{1}, \eta_{2}\right)+\frac{1}{\alpha_{s}^{2}} \frac{\partial^{2}}{\partial \eta_{2}^{2}} \psi\left(\eta_{1}, \eta_{2}\right)=0
\end{aligned}
$$

where $\alpha_{l}=\sqrt{1-\left(v_{I I}^{2} / c_{l}^{2}\right)}, \alpha_{s}=\sqrt{1-v_{I I}^{2} / c_{s}^{2}}$, and $c_{l}, c_{s}$ are the longitudinal (pressure) and the shear wave speeds, respectively.

[20] The general solutions of equation (2) for the displacement potentials are

$$
\begin{aligned}
& \phi\left(\eta_{1}, \eta_{2}\right)=\operatorname{Re}\left\{F\left(z_{l}\right)\right\}, \\
& \psi\left(\eta_{1}, \eta_{2}\right)=\operatorname{Im}\left\{G\left(z_{s}\right)\right\},
\end{aligned}
$$

where $F()$ and $G()$ are analytic functions everywhere except on the rupture faces with respect to their arguments $z_{l}=\eta_{1}+i \alpha_{l} \eta_{2}$ and $z_{s}=\eta_{1}+i \alpha_{s} \eta_{2}$, respectively. The dynamic stress fields may now be expressed in terms of the unknown functions $F, G$ as

$$
\begin{gathered}
\sigma_{11}\left(\eta_{1}, \eta_{2}\right)=\mu \operatorname{Re}\left\{\left(1-\alpha_{s}^{2}+2 \alpha_{l}^{2}\right) F^{\prime \prime}\left(z_{l}\right)+2 \alpha_{s} G^{\prime \prime}\left(z_{s}\right)\right\}+T, \\
\sigma_{22}\left(\eta_{1}, \eta_{2}\right)=-\mu \operatorname{Re}\left\{\left(1+\alpha_{s}^{2}\right) F^{\prime \prime}\left(z_{l}\right)+2 \alpha_{s} G^{\prime \prime}\left(z_{s}\right)\right\} \\
\sigma_{12}\left(\eta_{1}, \eta_{2}\right)=-\mu \operatorname{Im}\left\{2 \alpha_{l} F^{\prime \prime}\left(z_{l}\right)+\left(1+\alpha_{s}^{2}\right) G^{\prime \prime}\left(z_{s}\right)\right\}
\end{gathered}
$$

where $T$ is the $T$ stress term in the crack tip stress field. The $\mathrm{T}$ stress term represents a constant (static) direct stress acting parallel to the fault plane. As we will see later, its magnitude can be related to the magnitude of the far-field tectonic load as well as the angle of inclination of the fault to the principal axes of far-field stress.

[21] For a mode II rupture, the displacement field $u_{1}$ is antisymmetric, while $u_{2}$ is symmetric with respect to $\eta_{2}$. Consequently, at the rupture plane $\left(\eta_{2} \rightarrow 0\right)$, the symmetry of $F$ and $G$ can be established as

$$
\begin{aligned}
& F^{\prime \prime}+\left(\eta_{1}\right)=-\bar{F}^{\prime \prime}-\left(\eta_{1}\right), \\
& G^{\prime \prime}\left(\eta_{1}\right)=-\bar{G}^{\prime \prime}\left(\eta_{1}\right),
\end{aligned}
$$

where the superscript plus and minus stand for the limits $\eta_{2} \rightarrow 0^{+}$(upper rupture face) and $\eta_{2} \rightarrow 0^{-}$(lower rupture face), respectively.

[22] Functions $F$ and $G$ can be determined from the traction boundary conditions on the rupture faces which, following Samudrala et al. [2002], are given by

$$
\begin{array}{lr}
\left(\sigma_{22}\right)^{ \pm}\left(\eta_{1}\right)=0 & \eta_{1}<0, \\
\left(\sigma_{12}\right)^{ \pm}\left(\eta_{1}\right)= \begin{cases}\tau\left(\eta_{1} / L\right) & -L<\eta_{1}<0, \\
0 & \eta_{1}<-L\end{cases}
\end{array}
$$

where $\tau$ is the cohesive traction distribution acting on the cohesive surfaces, which, unlike the slip-weakening formulations utilized by Poliakov et al. [2002] and Rice et al. [2005], is unknown a priori. The constitutive description of $\tau$ is given by a linear velocity-weakening shear cohesive law [e.g., Freund and Lee, 1990; Samudrala et al., 2002], which relates the shear traction at any point within the zone to the local slip velocity $\dot{\delta} \equiv\left(\dot{u}_{1}^{+}-\dot{u}_{1}^{-}\right)$, as follows:

$$
\tau(\dot{\delta})=\tau_{0}\left[1+\beta^{*} \frac{\mu \dot{\delta}}{2 \tau_{0} c_{s}}\right] .
$$

In (8), $\mu$ is the shear modulus of the surrounding material, $\tau_{0}$ is the static shear strength of the interface and $\beta^{*}<0$ is a negative dimensionless velocity-weakening parameter that governs the severity of velocity weakening and eventually needs to be determined by experiment. Therefore, in this constitutive relationship, the shear traction decays from a peak value $\tau_{0}$ linearly with sliding velocity, $\dot{\delta}$, at the leading edge of the rupture to a residual value $\tau=0$ at the trailing edge, where the slip rate has magnitude $\dot{\delta}=\left(2 \tau_{p} c_{s}\right) /\left(\mu \beta^{*}\right)$ [Samudrala et al., 2002]. As described in section 2, the static strength $\tau_{0}$ is given by $\tau_{0}=\tau_{c}+f_{s} P \cos ^{2} \alpha$. In this expression, the first term, $\tau_{c}$, corresponds to the quasi-static cohesive strength of the interface in the absence of far-field compressive stress. The second term corresponds to the contribution of far-field stress and static friction to the interfacial strength, $f_{s}$ being the static coefficient of friction estimated by quasi-static experiments described by Griffith et al. [2009b, Figure 1c]. The total strength $\tau_{0}$ is the net quasistatic strength level encountered by the shear rupture tip (front of the translating cohesive zone) as it races along the interface. Within the cohesive zone, this level drops to zero due to the linear velocity-weakening law described in equation (8). The normal static stress comes indirectly into 


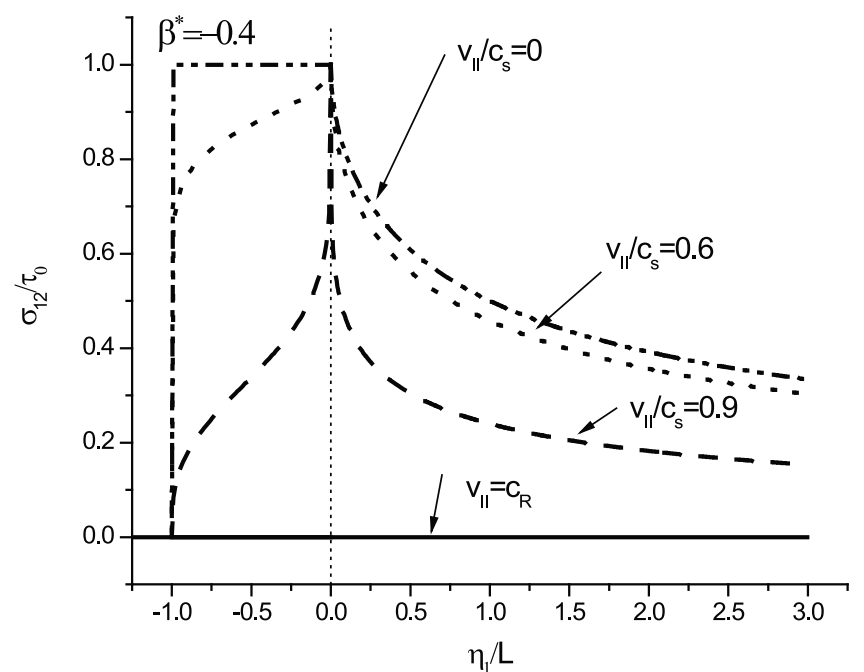

Figure 6. Normalized $\sigma_{12}$ distribution on the upper (or lower) rupture face.

the analysis through the dependence of the initial static shear strength of the bond $\left(\tau_{0}\right)$ on the normal component and on static friction coefficient. It should be noted that although the dependence of $\tau$ on sliding speed, $\dot{\delta}$, is linear, the spatial distribution of $\tau\left(\eta_{1} / L\right)$ within the cohesive zone is not and needs to be determined by solving the complete boundary value problem as posed above. An expression for this spatial distribution is obtained by recalling that the rupture model considered here is dynamic and steady state and as a result

$$
\dot{\delta}=\left(\dot{u}_{1}^{+}-\dot{u}_{1}^{-}\right)=-2 v_{I I} \frac{\partial u_{1}}{\partial \eta_{1}} .
$$

By substituting this equation into the constitutive description for the cohesive tractions, equation (8), the spatial distribution of $\tau$ is obtained as follows:

$$
\begin{aligned}
\tau\left(\frac{\eta_{1}}{L}\right)= & \left(\tau_{c}+f_{s} P \cos ^{2} \alpha\right)\left[1+\left|\beta^{*}\right| \frac{v_{I I}}{c_{s}} \frac{\mu}{\left(\tau_{c}+f_{s} P \cos ^{2} \alpha\right)} \frac{\partial u_{1}}{\partial \eta_{1}}\left(\frac{\eta_{1}}{L}\right)\right], \\
& -1<\frac{\eta_{1}}{L}<0 .
\end{aligned}
$$

From now on, we will refer to the front end of the cohesive zone as the mathematical rupture tip and to the rear end as the physical rupture tip. In the present model, the rupture surface tractions are all assumed to fall to zero behind the cohesive zone due to the influence of the velocity-weakening law.

[23] By solving the above equations subject to the boundary conditions (7), with a cohesive strength distribution given by (9) the normalized dynamic shear stress $\sigma_{12}$ distribution on the upper rupture face of the cohesive zone can now be obtained from [Samudrala et al., 2002] for the subsonic case of rupture speed as follows:

$$
\frac{\sigma_{12}}{\tau_{0}}=\frac{\tau}{\tau_{0}}=1+\frac{\sin \gamma \pi}{\pi} \frac{\left(-\eta_{1} / L\right)^{\gamma+1 / 2}}{\left(1+\eta_{1} / L\right)^{\gamma}} \int_{0}^{1} \frac{(1-s)^{\gamma}}{\sqrt{s}\left(1+s \eta_{1} / L\right)} d s,
$$

where

$$
\gamma=\frac{1}{\pi} \tan ^{-1}\left[\beta^{*} \frac{v_{I I}^{3}}{c_{s}^{3}} \frac{\alpha_{s}}{R\left(v_{I I}\right)}\right]<0, R\left(v_{I I}\right)=4 \alpha_{l} \alpha_{s}-\left(1+\alpha_{s}^{2}\right)^{2}
$$

is the Rayleigh function. Equation (10) also holds for the dynamic shear stress $\sigma_{12}$ on the lower rupture face, due to the antisymmetry in (5). Figure 6 shows the distribution of dynamic shear stress $\sigma_{12}$ on the upper (or lower) rupture face of the cohesive zone with velocity weakening. The dynamic shear stress decreases monotonically from $\tau_{0}$ at the mathematical rupture tip and approaches zero at the physical rupture tip.

[24] The distribution of the normalized dynamic stress component, $\sigma_{11}$, on the upper rupture face of the cohesive zone is given by (see Appendix A)

$$
\begin{aligned}
\frac{\sigma_{11}}{\tau_{0}}= & -\frac{4}{\pi} \frac{\left(\alpha_{l}^{2}-\alpha_{s}^{2}\right) \alpha_{s}}{R\left(v_{I I}\right)} \frac{\left(-\eta_{1} / L\right)^{\gamma+1 / 2}}{\left(1+\eta_{1} / L\right)^{\gamma}} \cos \gamma \pi \\
& \cdot \int_{0}^{1} \frac{(1-s)^{\gamma}}{\sqrt{s}\left(1+s \eta_{1} / L\right)} d s+\frac{T}{\tau_{0}} .
\end{aligned}
$$

On the lower rupture face, however, because of the symmetry of $F$ and $G$, as shown in equation (5), the normalized dynamic stress component $\sigma_{11}$ is different from equation (11) and features a change in sign only in its first term. The direct stress component, acting parallel to the fault line, now becomes

$$
\begin{aligned}
\frac{\sigma_{11}}{\tau_{0}}= & \frac{4}{\pi} \frac{\left(\alpha_{l}^{2}-\alpha_{s}^{2}\right) \alpha_{s}}{R\left(v_{I I}\right)} \frac{\left(-\eta_{1} / L\right)^{\gamma+1 / 2}}{\left(1+\eta_{1} / L\right)^{\gamma}} \cos \gamma \pi \\
& \cdot \int_{0}^{1} \frac{(1-s)^{\gamma}}{\sqrt{s}\left(1+s \eta_{1} / L\right)} d s+\frac{T}{\tau_{0}} .
\end{aligned}
$$

It should be note that the $T$ term in (12) does not change sign as one moves from the upper to the lower rupture faces. It represents a constant background prestress state which also trivially satisfies both the governing equations and the boundary conditions of the rupture problem as stated above. Its magnitude can be related to the applied prestress on the specimen boundaries and to the fault inclination angle.

[25] It is also important to note that, with a velocityweakening cohesive zone $\left(\beta^{*}<0\right)$ at the physical rupture tip $\left(\eta_{1} / L=-1\right)$, when $v_{I I} \neq 0, \sigma_{11} / \tau_{0}$ reaches a finite value given by

$$
\lim _{\frac{\eta_{1}}{L} \rightarrow-1} \frac{\sigma_{11}}{\tau_{0}}=4 \frac{\left(\alpha_{l}^{2}-\alpha_{s}^{2}\right) \alpha_{s}}{R\left(v_{I I}\right)} \frac{\cos \pi \gamma}{\sin \pi \gamma}+\frac{T}{\tau_{0}}
$$

on the upper rupture face and by

$$
\lim _{\frac{\eta_{1}}{L} \rightarrow-1} \frac{\sigma_{11}}{\tau_{0}}=-4 \frac{\left(\alpha_{l}^{2}-\alpha_{s}^{2}\right) \alpha_{s}}{R\left(v_{I I}\right)} \frac{\cos \pi \gamma}{\sin \pi \gamma}+\frac{T}{\tau_{0}}
$$

on the lower face of the rupture. In contrast, in the absence of velocity weakening $\left(\beta^{*}=0\right), \sigma_{11}$ is singular at the physical crack tip (back of cohesive zone) similar to the asymptotic solution of Freund [1990] for a mode II crack with no end zone.

[26] The uniform $\mathrm{T}$ stress field is related to the external compressive load $-P$ by $T=-P \sin ^{2} \alpha(<0)$ in our loading 


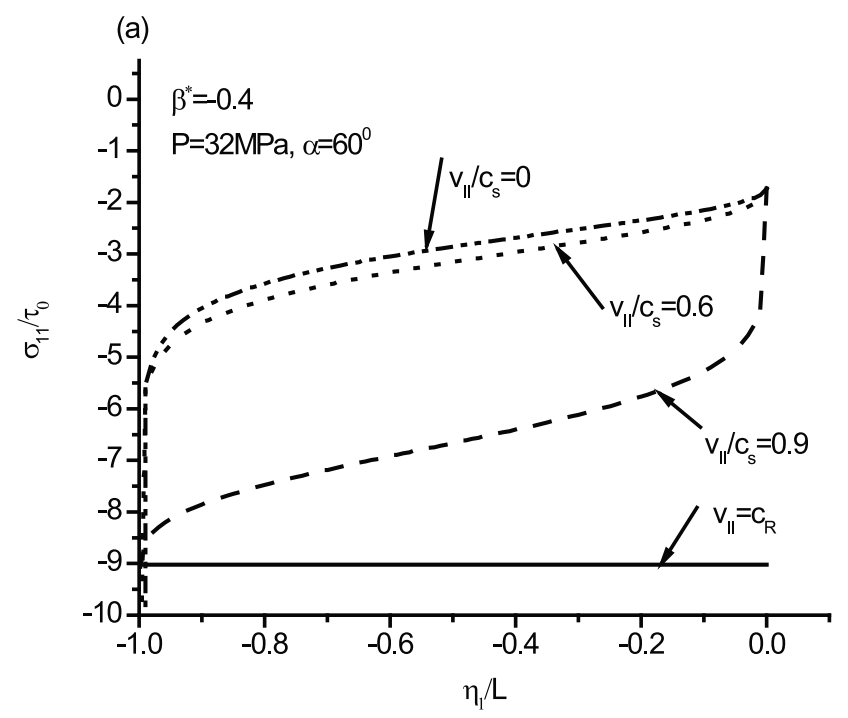

(b)

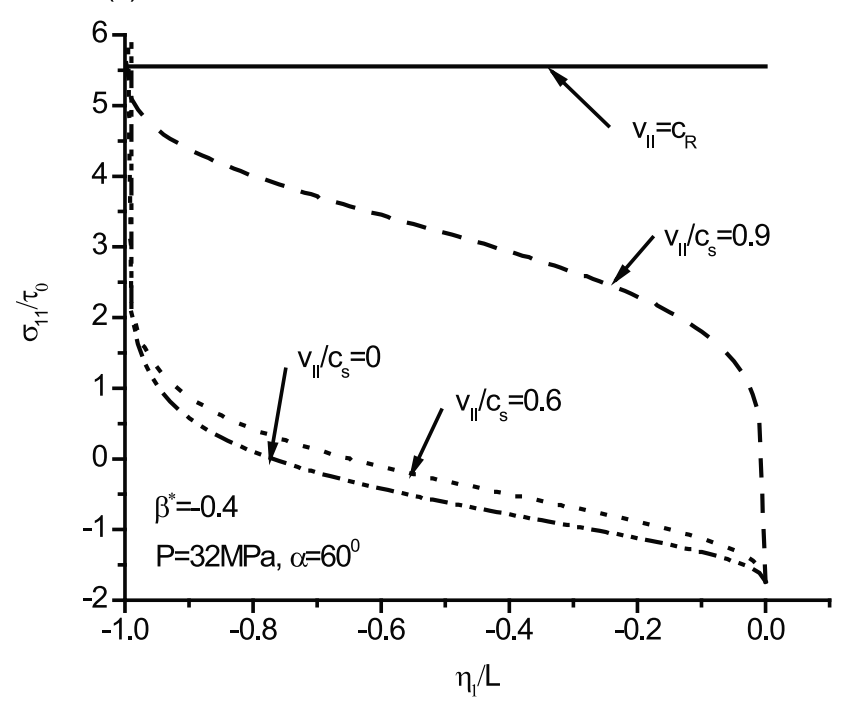

Figure 7. Normalized $\sigma_{11}$ distribution on (a) upper rupture face and (b) lower rupture within the cohesive zone.

configuration. In the Earth's crust it can similarly be related to the far-field, biaxial, tectonic load.

[27] Figures $7 \mathrm{a}$ and $7 \mathrm{~b}$ show the distribution of the dynamic stress, $\sigma_{11}$, on the upper and lower faces of the rupture plane, respectively. The different curves correspond to various levels of rupture speed. Results are shown for $\beta^{*}=-0.4, P=32 \mathrm{MPa}$ and $\alpha=60^{\circ}$.

\section{Predicting the Orientation of Secondary Tensile Cracks}

[28] Both Homalite-100, used in the experiments, and crustal rock surrounding natural faults in real earthquake events are nominally brittle solids. Consequently, we assume that they obey the maximum principal stress criterion for brittle fracture. Equivalently, we assume that the secondary, mode I, cracks observed in the experiments and on exhumed faults would initiate on the side of the fault and at locations which, locally and instantaneously, experience tensile stresses as the dynamic shear rupture passes by. For right-lateral slip, as in the present study, this is the lower face of the main shear rupture. In particular, these secondary (mode I) cracks would initiate at positions at the lower surface of the fault plane (weak bond) where the maximum stress equals the ultimate tensile strength of the monolithic material. Also, it is expected that their initial direction of growth will be perpendicular to the maximum principal stress direction at such locations. At points adjacent to the cohesive zone, the dynamic stress component $\sigma_{11}$ always is negative (compression) on the upper surface. On the lower surface of the fault plane however, $\sigma_{11}$ could attain positive (tensile) values near the physical crack tip as is clearly shown in Figure $7 \mathrm{~b}$. The exact location at which $\sigma_{11}$ changes sign depends on the relative magnitude of the negative T term $\left(T=-P \sin ^{2} \alpha\right)$ compared to the positive, dynamic first term in equation (12).

[29] As anticipated, the rupture speed $v_{\mathrm{II}}$, far-field tectonic load $P$, the angle $\alpha$, as well as the static strength $\tau_{0}$ and the velocity-weakening parameter $\beta^{*}$, all contribute to identifying the location along the bottom faces of the fault line where this stress component may first become positive. The relevant stress, however, which governs the initiation of the tensile crack is the maximum principal stress, $\sigma_{1}$, rather than $\sigma_{11}$ itself. A two-dimensional Mohr circle analysis may be used to show that this stress on the upper surface of the shear cohesive zone is always less than that on the lower surface, and the latter may become large enough, close to the physical rupture tip, to reach the Homalite strength $\sigma_{H}$ and thus initiate tensile fractures. To investigate such conditions, the stress state illustrated in Figure 8, is used to calculate the maximum principal stress $\sigma_{1}$ and the inclination angle $\theta$ of the principal plane relative to the horizontal (fault plane) as follows:

$$
\begin{gathered}
\sigma_{1}=\frac{\sigma_{11}}{2}+\sqrt{\left(\frac{\sigma_{11}}{2}\right)^{2}+\sigma_{12}^{2}}, \\
\theta=\frac{\pi}{2}-\frac{1}{2} \arctan \left(\frac{2 \sigma_{12}}{\sigma_{11}}\right) .
\end{gathered}
$$

Figure 9 shows the variation of the normalized principal stress, $\sigma_{1} / \tau_{0}$, and the principal angle, respectively. These are plotted for points within the cohesive zone, $-L \leq \eta_{1} \leq 0$, and on the lower rupture face. They correspond to $P=32 \mathrm{MPa}$, $\alpha=60^{\circ}, v_{I I} / c_{s}=0.6$ and $\beta^{*}=-0.4$. They are obtained by substituting equations (10) and (12) into equations (15)

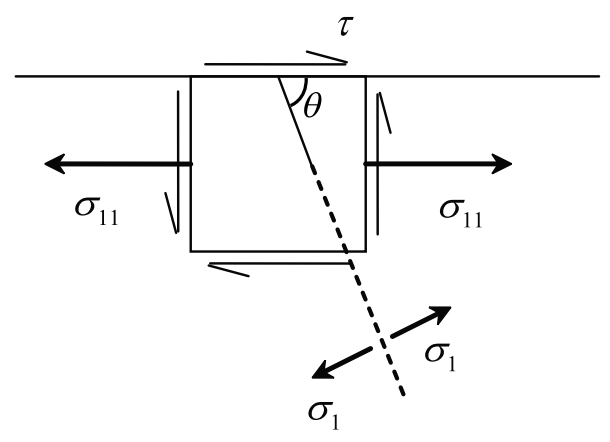

Figure 8. Stress state on the lower rupture surface. 


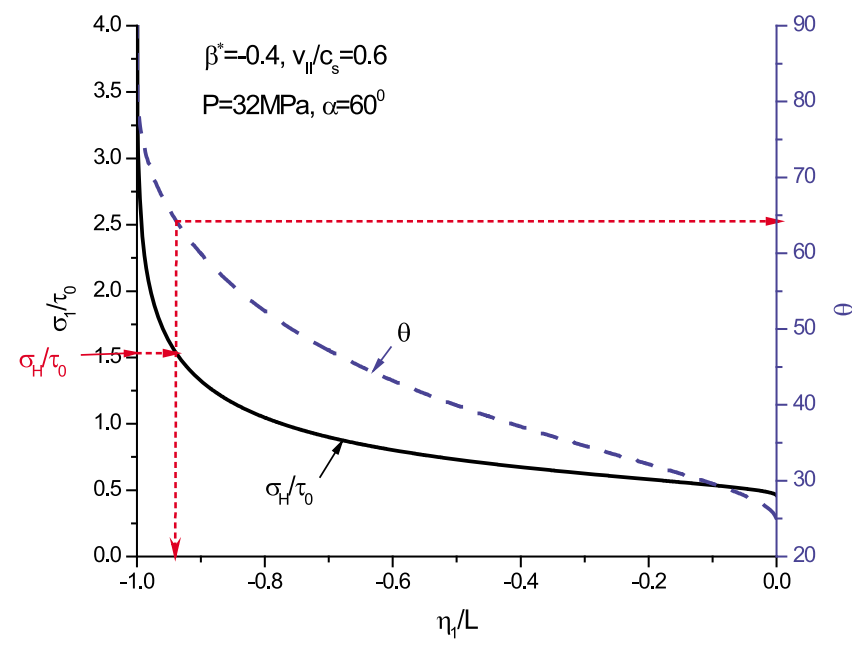

Figure 9. Method to determine the mode I crack inclination angle.

and (16), respectively. As discussed above, the principal stress remains positive in a small region at the trailing end of the shear cohesive zone, allowing the maximum tensile stress fracture criterion to be satisfied somewhere in that vicinity.

[30] Plots in the form of Figure 9 can be used to predict the initial inclination angle of the secondary microcracks for various loading configurations, $(P, \alpha)$, sub-Rayleigh shear rupture speeds, $v_{I I} / c_{s}$ and velocity-weakening parameters, $\beta^{*}$. This is done by indicating the critical level for fracture initiation $\left(\sigma_{1}=\sigma_{H}\right)$ on the left vertical axis of Figure 9. This allows for the identification of the location on the fault line (ordinate of Figure 9) where the first secondary crack will initiate (see arrow from the left vertical axis of Figure 9). By considering the same location, the corresponding inclination angle, $\theta$, can be obtained as indicated by the arrow for the right vertical axis in Figure 9.

\section{Microcrack Inclination Angle: Theory Versus Experiment}

[31] In section 2, we have seen that the laboratory experiments of Griffith et al. [2009b] clearly revealed a significant correlation between $\theta$ and system parameters such as rupture speed, $v_{I I}$, and tectonic loading $(P, \alpha)$. The model presented above also shows that in addition to $v_{I I}, P$ and $\alpha$, other parameters, such as the static bond strength, $\tau_{0}$, the velocity-weakening rate, $\beta^{*}$, and the tensile strength of monolithic Homalite, $\sigma_{H}$, are also involved in determining $\theta$.

[32] While some of the above discussed parameters are easily measurable from independent experiments, others can only be estimated to vary within certain ranges of values. In particular the tensile strength of Homalite, $\sigma_{H}$, is reported to range from $18 \mathrm{MPa}$ to $28 \mathrm{MPa}$. In addition, there is currently no direct experimental information regarding the amplitude of the negative velocity-weakening parameter, $\beta^{*}$, for interfaces of the type considered in this study. Because $\sigma_{H}$ and $\beta^{*}$ are difficult to constrain given current literature, we treat these parameters as unknowns to be fitted by a single set of experimental conditions. When determined, these parameters are used in the theoretical model to predict the outcome of a series of subsequent experiments. The purpose of this exercise is to validate the model by checking its ability to determine the dependence of $\theta$ on $v_{I I}, \alpha$ and $P$.

[33] Experiment 60I $\left(P=32 \mathrm{MPa}, \alpha=60^{\circ}\right)$ was chosen to provide the best fit for $\sigma_{H}$ and $\beta^{*}$. The discrete points in Figure 10 represent the experimental dependence of $\theta$ on rupture speed $v_{I I}$, while the solid line is the result of the theoretical model for $\sigma_{H}=21 \mathrm{MPa}$ and $\beta^{*}=-0.61$. These values are chosen to provide the best fit to the experimental results of this particular experiment. In Figure 10, the effects of $\sigma_{H}$ and $\beta^{*}$ on the prediction of the inclination angle $\theta$ are also presented. The variations of $\theta$ along the rupture path (fault plane) for $\sigma_{H}=21 \mathrm{MPa}$ and $\beta^{*}=-0.61$ are shown in Figure 11.

[34] Using the above stated values for $\sigma_{H}$ and $\beta^{*}$ and the measured rupture speed history as input, the theoretical variation of $\theta$ along the rupture path can be computed for experiments number 70I and 70J $\left(P=38 \mathrm{MPa}, \alpha=70^{\circ}\right)$, and these predictions can be compared to the actual measurements of $\theta$. This comparison is shown in Figures 12a and $12 \mathrm{~b}$.

[35] It is observed that the model predictions reproduce the measured values of $\theta$ and the spatial variation of the secondary crack inclination angles well despite the fact that the static prestress conditions in experiment 60I (Figures 10 and 11) differ significantly from those in experiments $70 \mathrm{I}$ and 70J (Figure 12). It should also be noted that although experiments $70 \mathrm{I}$ and $70 \mathrm{~J}$ were nominally identical in loading configuration, they featured slightly different velocity histories due to uncontrollable differences in rupture nucleation conditions and load uniformity.

[36] Another way to view the same data is to concentrate on the dependence of $\theta$ on $v_{I I}$ for both 70I and 70J. The comparison between predictions and experiment for these cases are shown in Figures 13a and 13b. Close scrutiny of the above results reveals that for a given value of $P$, the dependence of $\theta$ on $v_{I I}$ is approximately linear. For fixed values of $\sigma_{H}$ and $\beta^{*}$, the level and slope of this line depends on the value of the far-field stress $P$ (see Figures 10 and 13).

[37] Finally, it should be noted that a separate set of experiments was performed for $P=56 \mathrm{MPa}, \alpha=80^{\circ}$. The rupture speed ranged from 0.7 to $0.9 c_{s}$. For these conditions, no secondary cracks were observed. Indeed, application of the theoretical model for this case confirms that the brittle fracture initiation criterion is never satisfied within the cohesive zone. For this case, the large value of $P$ (and the orientation of $P$ ) ensures that the maximum principal stress remains below $\sigma_{H}$ even at the trailing edge of the cohesive zone $\left(\eta_{1} / L \rightarrow-1\right)$. Another interesting point of comparison corresponds to cases in which no adhesive is applied on the rupture surfaces $\left(\tau_{c}=0\right)$. In such cases, the static bond strength is purely provided by the frictional resistance of the interface and is given by $\tau_{0}=f_{S} P \cos ^{2} \alpha$. Here, the maximum angles which can be tested are less than $\tan ^{-1} f_{s}$, since for higher angles the two pieces of the specimen cannot be held together by static friction. Such experiments are described in a review by Rosakis et al. [2007] and more recently by Lu et al. [2009]. In these cases $f_{s}$ was measured to equal 0.6 and the maximum fault angle tested was $30^{\circ}$. The load levels $P$, for which the ruptures were sub-Rayleigh $\left(v_{I I} \sim 0.99 c_{R}\right)$, ranged from 3 to $10 \mathrm{MPa}$. In many of these cases the experiments show that there are no tensile cracks generated. 


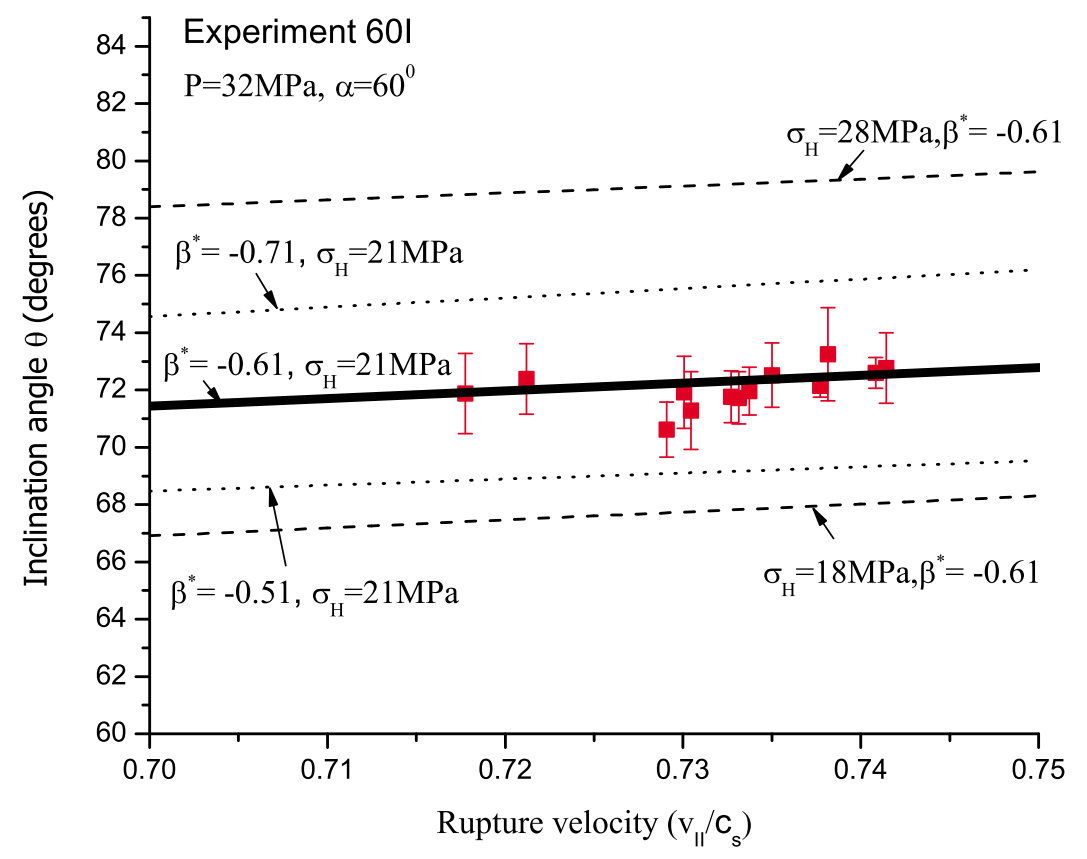

Figure 10. Theoretical and experimental inclination angle, $\theta$, with respect to crack speed for experiment 60I. The theoretical predictions of $\theta$ for different combinations of $\sigma_{H}$ and $\beta^{*}$ are presented to show the effects of these parameters on the inclination angle $\theta$. This experiment provides best fit values for $\sigma_{H}$ and $\beta^{*}$. This experiment provides best fit values for $\sigma_{H}$ and $\beta^{*}$.

More specifically, when $\alpha=30^{\circ}, P=10 \mathrm{MPa}$, and when $\alpha=25^{\circ}, P=10 \mathrm{MPa}$ (two cases considered by $\mathrm{Lu}$ et al. [2007]), the present theory confirms once again that the brittle fracture criterion is not satisfied for any of the above stated pair of $\alpha$ and $P$. The reason this time is not the "large" value or relative orientation of $P$. Instead it is the "small" levels of frictional bond strength and the high values of $v_{I I}$ which determines the outcome. This is the case when cohesion is completely removed and $\tau_{c}=0$. Inherently, stronger bond strength, $\tau_{0}$, will encourage tensile failure of the host rock since the first term in (unnormalized version of) equation (12) is proportional to $\tau_{0}$, allowing it to overcome the second term which represents the contribution of the compressive static prestress. At the same time, for larger bond strengths, larger $P$ values would be necessary to initiate shear rupture along the fault interface. This larger $P$ value would increase the second term in equation (12). This demonstrates the delicate balance between the static prestress state and secondary tensile failure (or lack of tensile failure). When $\alpha=80^{\circ}$, it is extremely difficult for the transient direct stress to exceed $\sigma_{\mathrm{H}}$, which is consistent with our experimental observations.

[38] Our dynamic model used to predict the inclination of the microcracks assumes a zero normal stress component $\left(\sigma_{22}\right)$ on the rupture faces, which is consistent with the view of the dynamic rupture as a purely mode II rupture. In performing the analysis we had the choice to either ignore the uniform static prestress or to violate boundary conditions by artificially adding its constant contribution in the calculation of secondary crack directions and in the process violating the boundary conditions. We chose the former route in the absence of a more rigorous alternative. Indeed, our model only admits the existence of static prestress indirectly as controlling the initial static strength of the interface through the static coefficient of friction (see equation (9)). However, its obvious success in predicting microcrack orientation in multiple experiments seems to point out that the direct omission of static prestress in the calculation does not result in serious loss of the model's predictive power.

\section{Application to Exhumed Faults}

[39] The analytical model described in section 4, successfully predicts (1) the presence of secondary, mode I,

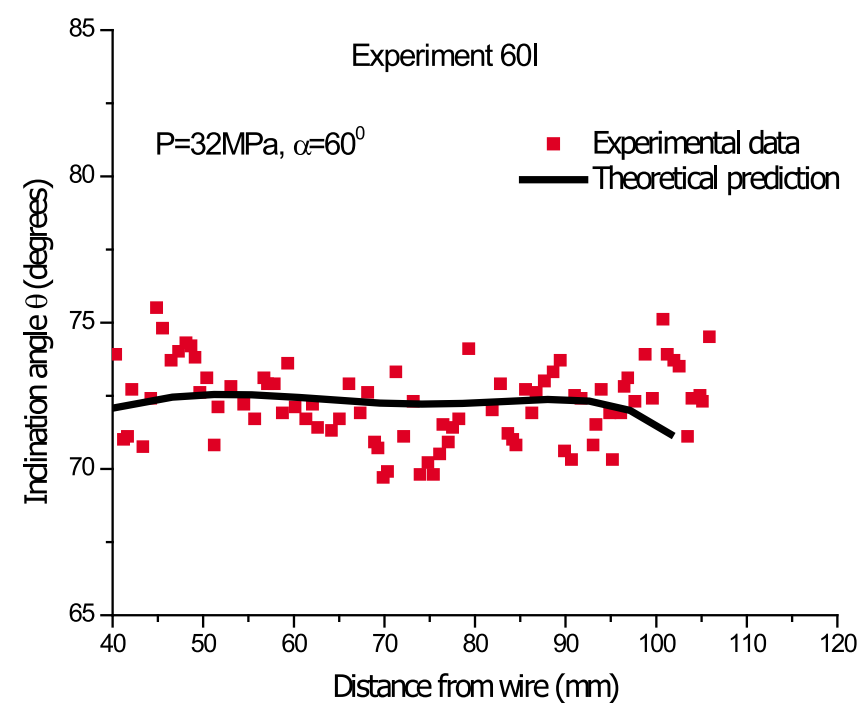

Figure 11. Theoretical and experimental inclination angle, $\theta$, with respect to rupture distance from wire in experiment $60 \mathrm{I}$. 
(a)

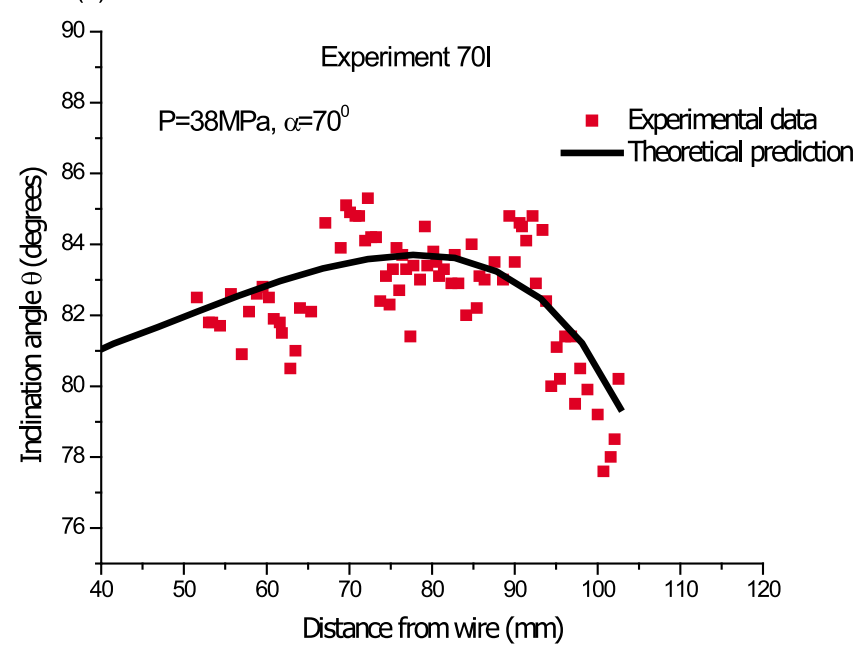

(b)

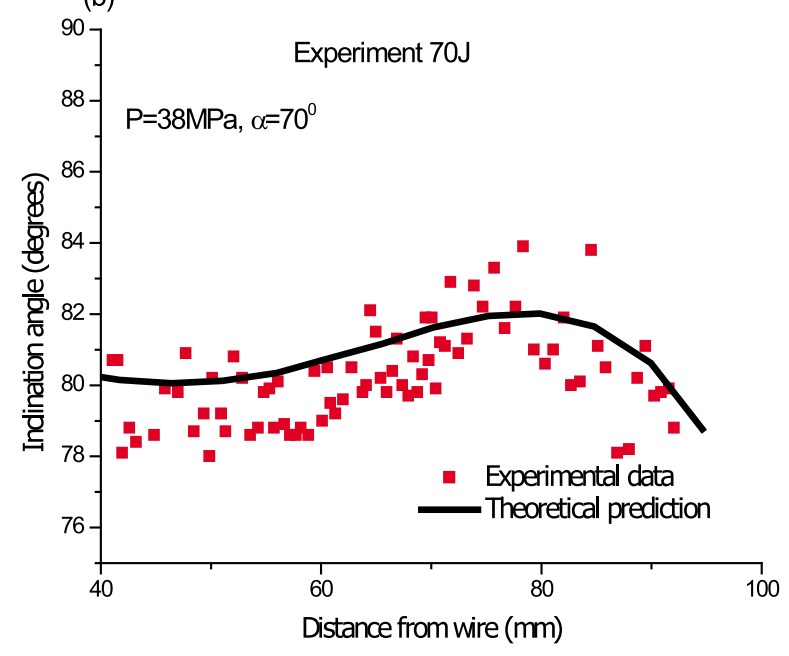

Figure 12. Model predictions and experimental measurements of inclination angle, $\theta$, with respect to rupture distance from wire in experiments (a) 70I and (b) 70J.

cracks and (2) their inclination angles relative to the main shear rupture generated in the laboratory regardless of prestress condition with a single velocity-weakening parameter, $\beta^{*}$. This apparent versatility of the analytical model encourages us to attempt its generalization and application to earthquake ruptures propagating along frictional faults separating crustal rocks. The most extensive data set of such quasiperiodic crack arrays (pseudotachylyte injection veins) was collected by Di Toro et al. [2005a] along the Gole Larghe Fault in tonalite (granodiorite) rocks of the Adamello batholith in the Italian Alps and the inclination angle $\theta$ of the most predominant set was observed to be approximately $\theta=90^{\circ}$. In this section, we attempt to estimate the inclination angle of these secondary cracks using model parameters that are chosen to be close to the inferred conditions of the Gole Larghe Fault. To predict the inclination angle $\theta$, we need to determine six parameters in the analytical model that depend on the material, characteristics of the rupture interface, and the tectonic setting: $\sigma_{\mathrm{T}}, \beta^{*}, f_{\mathrm{s}}, P, \alpha$, and $v_{\mathrm{II}}$, where $\sigma_{\mathrm{T}}$ is the tensile strength of the host rock. Of these model parameters $\beta^{*}$ and $f_{\mathrm{s}}$ define the sliding friction coefficient $f_{\mathrm{d}}$ by equation (8), and $P$ and $\alpha$ describe the tectonic prestress state.

[40] Following Di Toro et al. [2005b], we assume that the strike-slip faulting stress state condition is "Andersonian": the vertical principal stress, $\sigma_{2}$, equals the average of the two horizontal principal stresses $\sigma_{1}=P$ and $\sigma_{3}=b P(0<b<1)$ (Figure 14a). The equivalent adjustment for the experimental configuration for a biaxial stress state is illustrated in Figure $14 \mathrm{~b}$. At a given depth and due to gravity the vertical stress $\sigma_{2}$ is equal to $\sigma_{v}=\rho g z(1-\lambda)$, where $\rho=2740 \mathrm{~kg} \mathrm{~m}^{-3}$ is the density of the granodiorite rock [Arndt et al., 1997], $g$ is the acceleration of gravity and pore fluid factor $\lambda=0.4$ corresponds to a state of hydrostatic fluid pressure. Note that the choice of hydrostatic fluid pressure is based on alignment with that of Di Toro et al. [2005b]. While recent studies have indicated that meteoric water was not present during pseudotachylyte generation, isotopic composition of pseudotachylytes of the Gole Larghe Fault Zone differ from the wall rock materials, suggesting that some pore fluid may have been present during seismic faulting [Mittempergher et al., 2009]. As shown below, reducing the

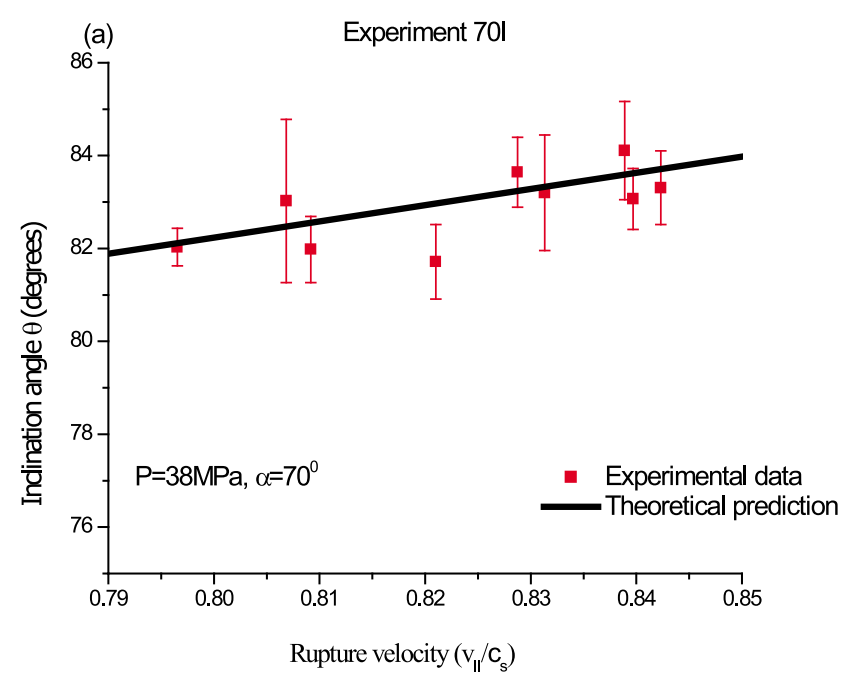

(b)

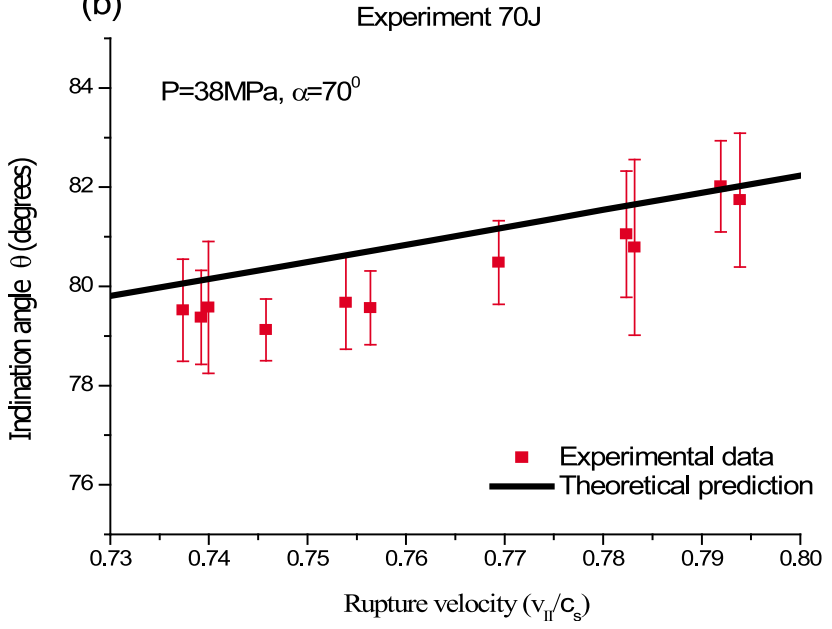

Figure 13. Predicted and experimental inclination angle, $\theta$, as a function of shear rupture speed (a) experiment 70 I and (b) experiment $70 \mathrm{~J}$. 

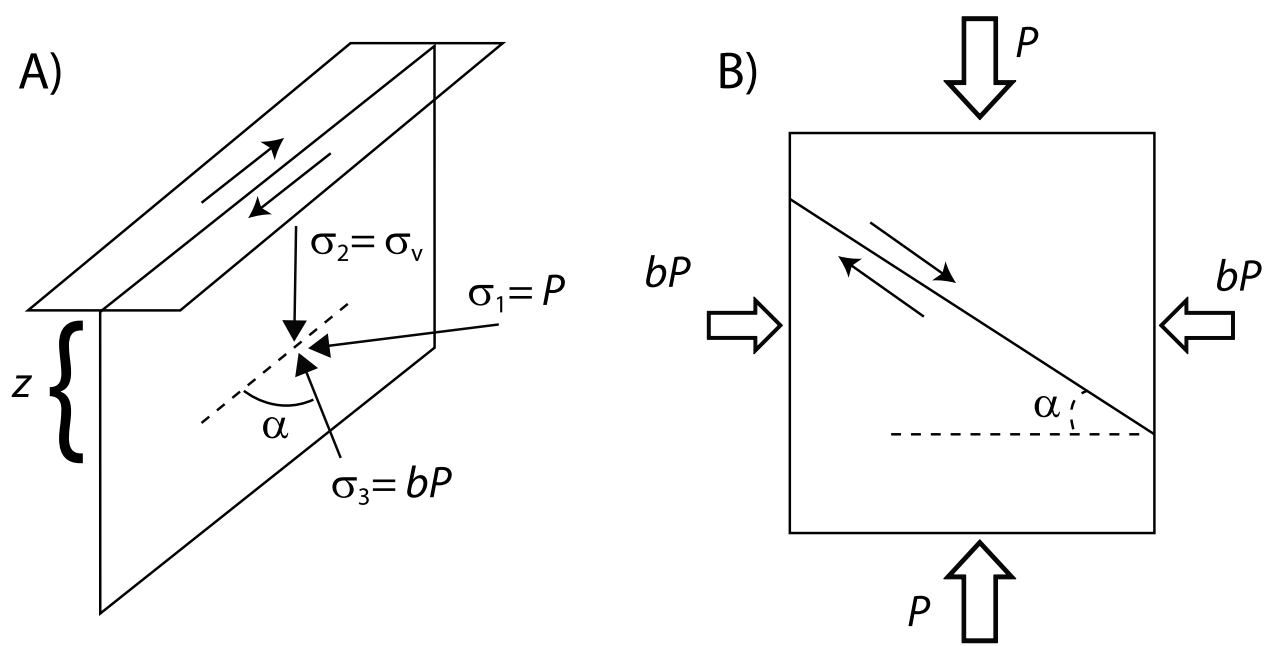

Figure 14. (a) Schematic of the strike-slip fault and the assumed "Andersonian" stress state [Sibson, 1974]. (b) Schematic of the biaxial loading in the horizontal plane of the fault.

pore fluid factor will change the magnitude of the principal stresses acting on the fault, but not the orientation. The depth of the fault section under scrutiny is denoted by $z$ and for our purposes will range between 5 and $10 \mathrm{~km}$. Frictional sliding on the fault is initiated when $b$ reaches its critical value given by

$$
\boldsymbol{b}_{\text {crit }}=\frac{\sin 2 \alpha-\boldsymbol{f}_{s}(\cos 2 \alpha+1)}{\sin 2 \alpha-\boldsymbol{f}_{s}(\cos 2 \alpha-1)},
$$

while the corresponding critical inclination angle $\alpha$ of the fault is

$$
\alpha_{c r i t}=\frac{\pi}{2}-\frac{1}{2} \tan ^{-1}\left(1 / \boldsymbol{f}_{s}\right)
$$

[Sibson, 1974]. At high confining pressures, the static coefficient of friction $f_{\mathrm{s}}$ of rocks varies from 0.6 to 0.85 according to Byerlee [1978] which give us estimates for $b_{\text {crit }}$ and $\alpha_{\text {crit. }}$. For example, $f_{\mathrm{s}}=0.75$ gives $b_{\text {crit }}=0.25$ and $\alpha_{\text {crit }}=63.5^{\circ}$, while $f_{\mathrm{s}}=0.6$ gives $b_{\text {crit }}=0.32$ and $\alpha_{\text {crit }}=60^{\circ}$. At the time frictional sliding occurs, the principal stress $\sigma_{2}$ can be related to $\sigma_{1}$ and $\sigma_{3}$ as $\sigma_{2}=\sigma_{v}=\left(\sigma_{1}+\sigma_{3}\right) /$ $2=\left(1+b_{\text {crit }}\right) P_{\text {crit }} / 2$ [Sibson, 1974]. Therefore, the critical compressive prestress $P_{\text {crit }}$ can be determined from $\sigma_{\mathrm{v}}$ as

$$
\boldsymbol{P}_{\text {crit }}=\frac{2 \rho \boldsymbol{g} \boldsymbol{z}(1-\lambda)}{1+\boldsymbol{b}_{\text {crit }}}
$$

and it depends on both the depth of the fault and the static coefficient of friction $f_{\mathrm{s}}$.

[41] For the case of the Gole Larghe Fault Zone, the above estimates of angle $\alpha_{c r i t}$ close to or above $60^{\circ}$ is supported by two lines of geological evidence. First, pseudotachylytebearing faults have been described based on field evidence as being "strong" faults, supporting large stress drops and therefore large coefficients of static friction [e.g., Griffith et al., 2009a; Sibson and Toy, 2006]. This would imply that the maximum compressive stress is oriented at a much more acute angle than indicated by recent evidence along major transverse plate boundary faults like the San Andreas Fault [e.g., Fialko et al., 2004; Hickman and Zoback, 2004], but more in line with estimates based on intraplate deep borehole and seismic measurements [e.g., Townend and Zoback, 2000; Zoback and Harjes, 1997].

[42] Second, microstructural evidence from along the Gole Larghe Fault Zone suggests that the direction of the maximum compressive stress was oriented at a low $\left(24^{\circ}-43^{\circ}\right)$ angle relative to the fault strike for some period of time before seismic slip occurred on the Gole Larghe faults. Figure 15 shows a potassium feldspar vein overprinted by a myrmekite, a vermicular intergrowth of the minerals quartz and sodic plagioclase which grows between potassium feldspar and plagioclase. While the role of stress in the formation of myrmekites is unclear in general [Vernon, 2004], myrmekites are found consistently in the contractional quadrants of plagioclase grains [Pennacchioni et al., 2006] in the tonalite rocks at the Gole Larghe Fault Zone, suggesting that they are a good indicator of the approximate orientation of principal stresses in this case. The large myrmekite in Figure 15 forms along a straight boundary between potassium feldspar and plagioclase, but not along straight boundaries in other orientations. If the straight grain boundary along which the large myrmekite is found is taken to be perpendicular to the maximum compressive stress, this implies $\alpha \approx 47^{\circ}$ (Figure 15). This interpretation is supported by the fact that the large myrmekite in Figure 15 overprints a potassium feldspar vein which is subparallel to the maximum compressive stress direction implied by the myrmekite. Assuming that the long axis of the vein parallels the most compressive stress direction this would imply a slightly steeper angle of $\alpha \approx 66^{\circ}$. These microstructures imply a roughly constrained range of $47^{\circ}<\alpha<66^{\circ}$. Our analytical estimates of $\alpha_{\text {crit }}$ described above lie well within this range. Because myrmekites are inferred to grow at higher ambient temperatures $\left(450^{\circ} \mathrm{C}-500^{\circ} \mathrm{C}\right.$ [Tribe and D'Lemos [1996]) than those inferred for seismic faulting along the Gole Large Fault $\left(250^{\circ} \mathrm{C}-300^{\circ} \mathrm{C}\right.$ [Di Toro and Pennacchioni, 2004]), it is impossible to say that the stress directions implied by evidence shown in Figure 15 were acting during seismic faulting, but based on the interpretation that the faults were active during rapid cooling of the host rock [Di Toro and Pennacchioni, 2004] this is not an unreasonable 


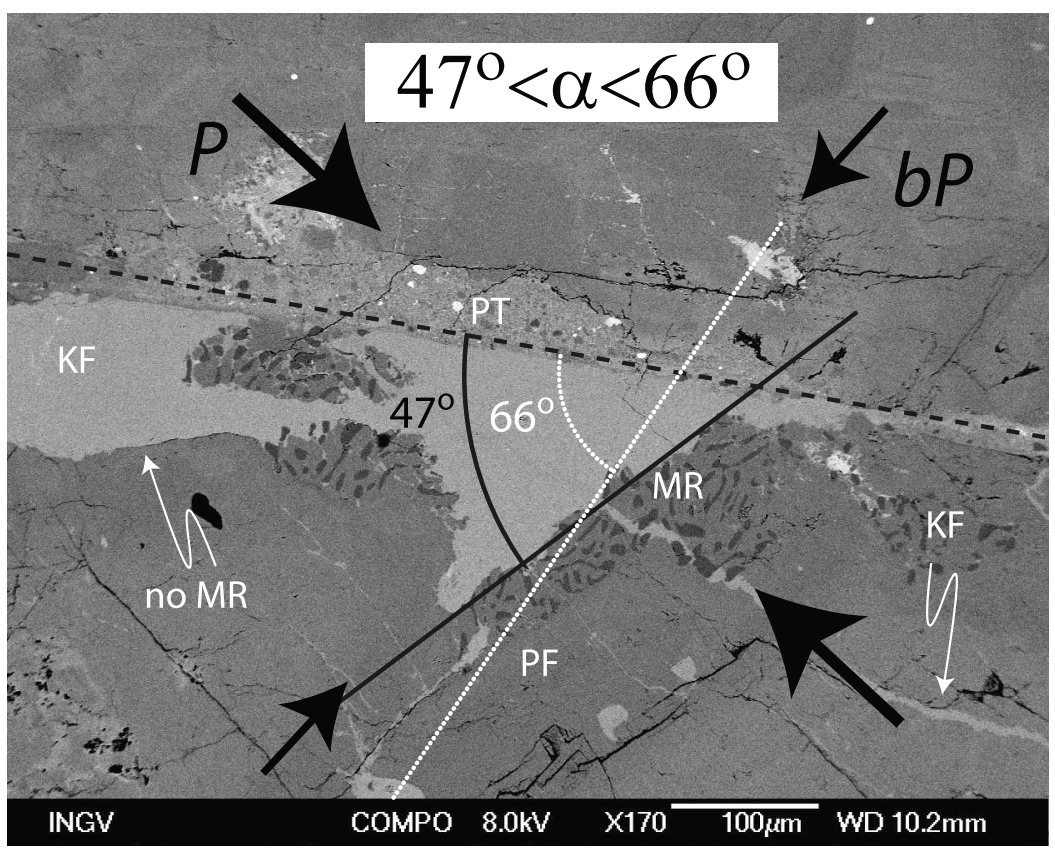

Figure 15. Scanning electron microscope image under backscattered electrons of a pseudotachylyte (PT) fault vein (black dashed line) along a fault strand from the Gole Larghe Fault. Myrmekite (MR), consisting of vermicular intergrowths of quartz (dark gray) and sodic plagioclase (medium gray) grows along a straight grain boundary between potassium feldspar (KF, light gray) and plagioclase feldspar (PF). Note no myrmekite is developed along the straight KF-PF grain boundary inclined at a shallower angle relative to the PT vein. This suggests that the direction of maximum compressive stress was roughly orthogonal to the straight grain boundary (traced by the solid black line) where myrmekite is developed. An older KF vein is oriented roughly orthogonal to the straight KF-PF grain boundary. The dotted white line is drawn roughly perpendicular to the trend of the KF vein, and the angle between this line and the trend of the PT fault vein gives $\alpha \approx 66^{\circ}$. Taking these pieces of evidence as upper and lower limits, respectively, $47^{\circ}<\alpha<66^{\circ}$. Arrows corresponding to our inferred directions of $P$ and $b P$ are drawn schematically.

assumption. From this point on, the value $f_{\mathrm{s}}=0.6$, which gives $b_{\text {crit }}=0.32$ and $\alpha_{\text {crit }}=60^{\circ}$, is chosen as the nominal static friction coefficient at depth in all calculations.

[43] Estimation of the velocity-weakening strength parameter $\beta^{*}$ is more difficult as the availability of experimental data on velocity weakening of crustal rocks at sliding speeds on the order of meters per second are sparse and are typically conducted at low values of normal stress, slow sliding velocities, or in analog geomaterials. In addition, at least at low sliding speeds, the velocity dependence of bare rock faces in contact varies considerably relative to values for granular materials such as fault gouge [e.g., Marone, 1998]. A number of studies have looked at the velocity dependence of sliding friction for granitoid rocks [e.g., Scholz and Engelder, 1976; Tullis and Weeks, 1986; Kilgore et al., 1993]; however, these studies were limited to sliding speeds between and $10^{-9}$ and $10^{-2} \mathrm{~m} \mathrm{~s}^{-1}$. Tsutsumi and Shimamoto [1997] showed a dramatic drop-off in sliding friction for gabbro, even prior to melting at sliding speeds greater than $10^{-2} \mathrm{~m} \mathrm{~s}^{-1}$. Beeler et al. [2008] use these data to show that the onset of weakening due to flash heating of asperities on the sliding surface can be shown to become significant at sliding speeds between 0.05 and $2 \mathrm{~m} \mathrm{~s}^{-1}$. However, these experiments were conducted at very low normal stresses $\left(\sigma_{n}=1.5 \mathrm{MPa}\right)$. For this analysis we explore the bounds of the linear velocity-weakening relationship based on the pair of fast sliding friction experiments described below.

[44] The first set of experiments was conducted on gabbro by Tsutsumi and Shimamoto [1997] at a normal stress of $\sigma_{n}=1.5 \mathrm{MPa}$. In these experiments, the coefficient of friction falls from its static level of $f_{s}=0.6$ to a dynamic level $f_{d}=0.48$ at sliding velocity, $\dot{\delta}$, of $0.6 \mathrm{~m} \mathrm{~s}^{-1}$. Taking $\tau=f_{d} \sigma_{n}$ and $\tau_{0}=f_{s} \sigma_{n}$, and using the parameters summarized in Table 1, one can use constitutive equation (3.8) to calculate $\beta^{*}=-0.06$ (Table 1). More recently, Yuan and Prakash [2008] used a modified torsional Kolsky bar apparatus to study velocity-dependent friction in two experiments for quartz-on-quartz interfaces at high pressures $\left(\sigma_{n}>60 \mathrm{MPa}\right)$ and sliding speeds $\left(\dot{\delta}>2 \mathrm{~m} \mathrm{~s}^{-1}\right)$. The slip distance in these experiments was limited to less than $5 \mathrm{~mm}$ due to the onset of microcracking of the quartz specimens; however, significant weakening was observed in both experiments. Following the methodology described above for the experimental results of Tsutsumi and Shimamoto [1997] and parameters listed in Table 1, the Yuan and Prakash [2008] results yield values of $\beta^{*}=-2.09$ and -1.23 , respectively. [45] In rocks such as granodiorites where pseudotachylytes and periodic fractures have been noted, quartz typically makes up less than $30 \%$ by volume [e.g., Di Toro et al., 2005b]. Melting in rocks is thought to be controlled by the lower melting point minerals (like biotite and muscovite), 
Table 1. Values Used to Estimate $\beta^{*}$ for Crustal Rocks

\begin{tabular}{|c|c|c|c|c|c|c|c|c|c|c|}
\hline Material & $\sigma_{n}(\mathrm{MPa})$ & $\dot{\delta}\left(\mathrm{m} \mathrm{s}^{-1}\right)$ & $\mu(\mathrm{MPa})$ & $\rho\left(\mathrm{kg} \mathrm{m}^{-3}\right)$ & $c_{s}\left(\mathrm{~m} \mathrm{~s}^{-1}\right)$ & $f_{s}$ & $f_{d}$ & $\tau(\mathrm{MPa})$ & $\tau_{0}(\mathrm{MPa})$ & $\beta^{*}$ \\
\hline Gabbro $^{a}$ & 1.5 & 0.6 & $35000^{\mathrm{b}}$ & 2900 & 3474 & 0.6 & 0.48 & 0.72 & 0.9 & -0.06 \\
\hline Quartz (Q01) & 62 & 2.2 & $44300^{\mathrm{d}}$ & 2700 & 4051 & 0.6 & 0.19 & 12 & 37.2 & -2.09 \\
\hline Quartz (Q02) & 65.5 & 4.05 & $44300^{\mathrm{d}}$ & 2700 & 4051 & 0.6 & 0.18 & 12 & 39.3 & -1.23 \\
\hline
\end{tabular}

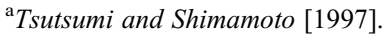

${ }^{\mathrm{c}}$ Yuan and Prakash [2008].

${ }^{\mathrm{b}}$ Ulrich et al. [2002].

${ }^{\mathrm{d}}$ Bass [1995].

and if we are to accept that flash heating is an important mechanism for weakening at or near the rupture front, similar logic also roughly applies (assuming the composition distribution for asperities is similar to the bulk rock). However, the experimental results of Yuan and Prakash [2008] show much stronger velocity weakening of pure quartz under pressures and sliding rates that are much more realistic for crustal rock sliding at seismogenic depth. Because more appropriate data does not exist at the current time, in our calculations, we use the value of $\beta^{*}=-1$ which is the average value of $\beta^{*}$ in the above estimated range from -2.09 to -0.06 . The accuracy in estimating the value of $\beta^{*}$ can be improved with future experiments. For example, experiments similar to Yuan and Prakash [2008] on both crustal rocks such as granodiorite and rock analog materials such as Homalite-100 at slip speeds $\left(1-10 \mathrm{~m} \mathrm{~s}^{-1}\right)$ and normal stress characteristic of seismogenic depths $\left(\sigma_{\mathrm{n}}>50 \mathrm{MPa}\right)$ would to improve on the current paucity of data in this parameter space. Facilities are under development that should supplement current understanding of the frictional behavior of geomaterials at seisomogenic slip speeds and normal stress [e.g., Niemeijer et al., 2009].

[46] Based on these estimated values of $\beta^{*}, f_{\mathrm{s}}, P, \alpha$, we can now obtain the relations of the inclination angle $\theta$ to the rupture speed $v_{\text {II }}$ at different depths. These are shown in Figure 16 as a function of rupture speed normalized by the Rayleigh wave speed. The three curves correspond to three hypothetical depths of the fault plane section under scrutiny. It should be noted that in order to generate Figure 16, a modification was introduced in the model to account for the biaxial loading conditions in the horizontal plane of the fault as shown in Figure 13b. Under such circumstances, the fault parallel T stress is given by $T=-P\left(\sin ^{2} \alpha+b \cos ^{2} \alpha\right)$ while the frictional strength as a function of sliding rate is now described by

$$
\begin{aligned}
\tau= & \tau_{\mathrm{c}}+f_{\mathrm{s}} P\left(\sin ^{2} \alpha+b \cos ^{2} \alpha\right) \\
& \cdot\left\{1-\beta^{*} \frac{\mu \dot{\delta}}{2 c_{s}\left[\tau_{c}+f_{\mathrm{s}} P\left(\sin ^{2} \alpha+b \cos ^{2} \alpha\right)\right]}\right\}
\end{aligned}
$$

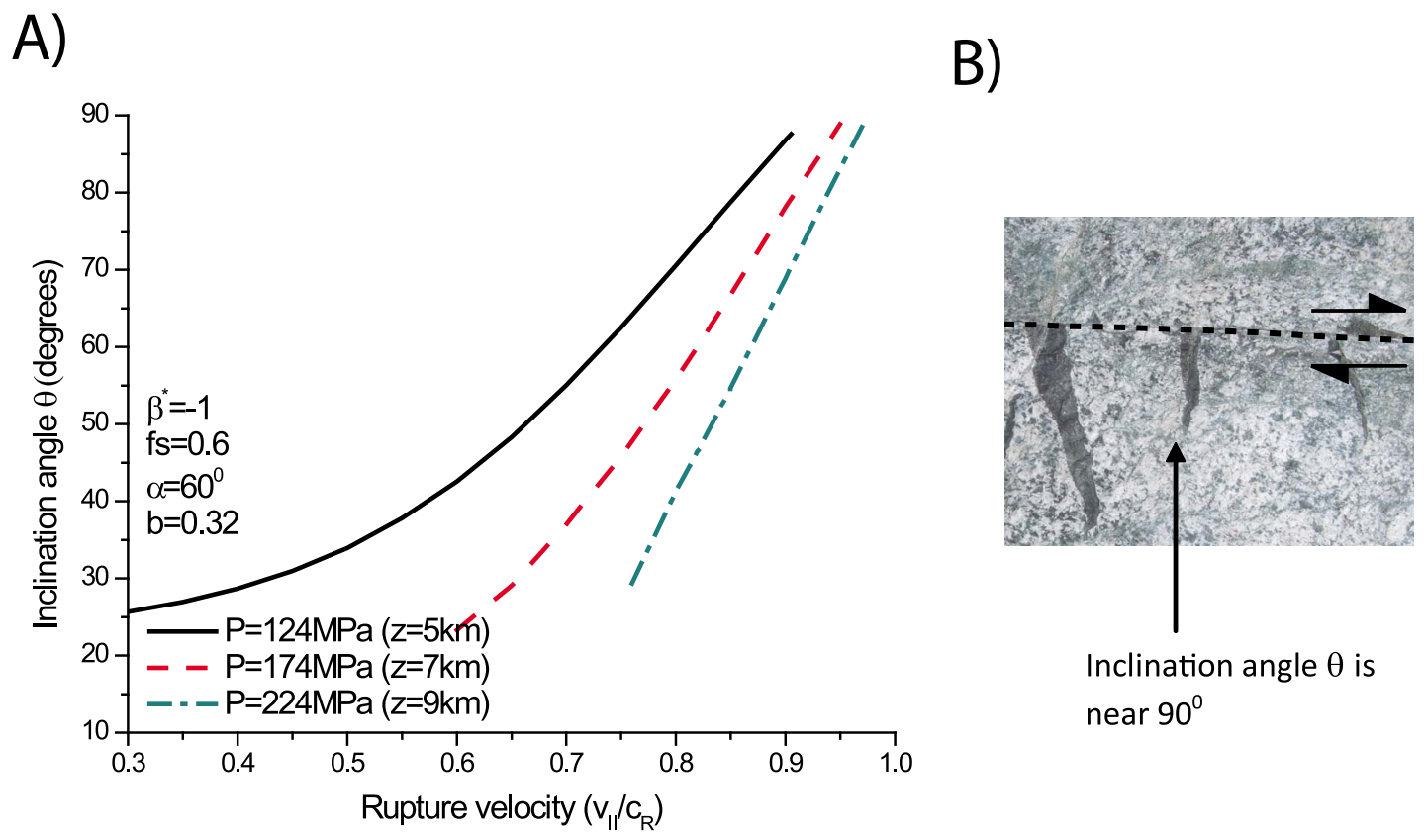

Figure 16. (a) Relations between the inclination angle of the secondary quasiperiodic cracks and the normalized rupture speed for different burial depths of the fault with the weakening parameter $\beta^{*}=-1$, a static coefficient of friction $f_{\mathrm{s}}=0.6$, a resulting biaxial ratio $b=0.32$ and an inclination angle of the fault $\alpha=60^{\circ}$. (b) Field image of cataclasite-pseudotachylyte-bearing faults showing near-vertical cracks $[D i$ Toro et al., 2005b]. 
with $\tau_{c}=0$ for purely frictional faults. The tensile strength of granitoid rocks $\sigma \mathrm{T}$ is chosen as $15 \mathrm{MPa}$, an average value, but can range between 3 and $38 \mathrm{MPa}$ [Bieniawski, 1984] and the Poisson ratio is 0.272 [Arndt et al., 1997].

[47] Figure 16 shows that for the depth of the fault from $5 \mathrm{~km}$ to $9 \mathrm{~km}$, when the rupture speed varies from $0.85 \mathrm{c}_{\mathrm{R}}$ to $0.98 c_{R}$ (the typical range of rupture speed in crustal earthquakes [Rosakis et al., 2007]), the inclination angle $\theta$ of the secondary cracks is in the range from $80^{\circ}$ to nearly $90^{\circ}$ which is close to the field observations and model calculations of Di Toro et al. [2005b]. It is necessary to mention that, at greater depth, because of the large compressive prestress together with small rupture speed, the maximum principal stress in the cohesive zone calculated by the model was observed to be greater than $\sigma_{\mathrm{T}}$ at every part of the cohesive zone. Therefore, the secondary crack inclination angles in these situations could not be determined by the present dynamic model. As a result the curves for $z=7 \mathrm{~km}$ and $9 \mathrm{~km}$ are interrupted as the speed drops to a low enough level as shown in Figure 16 (see the incomplete curves for $z=7 \mathrm{~km}$ and $9 \mathrm{~km}$ ). This example demonstrates the capability of the model to predict the correlations among the inclination angle of the secondary cracks, the rupture speed and the tectonic conditions for the natural faults.

\section{Conclusions}

[48] We present a dynamic fracture mechanics-based analytical description for steady state sub-Rayleigh shear rupture propagation utilizing a velocity-weakening cohesive zone model. The model predicts the occurrence and orientation of the tensile cracks which form in the material surrounding a weak rupture plane (fault) during laboratory experiments of shear rupture due to transient stress perturbations associated with the passage of the rupture tip. We identify the primary parameters controlling the nucleation and orientation of these tensile off-fault cracks and we illustrate through comparison with experiments that the analytical model is predictive in describing their morphology. The model is extrapolated to the study of natural faults and provides diagnostic criteria for interpreting velocity, directivity, and static prestress associated with past earthquake events recorded on exhumed faults.

[49] The results presented here indicate that some cracking observed along exhumed faults, particularly those distributed asymmetrically about the fault and filled by pseudotachylyte, are undoubtedly a result of dynamic loading in the form of a passing earthquake rupture tip. The fact that the formation of such dynamic cracks can be described in a quantitative fracture mechanics framework is remarkable on several levels. First, the geometry of these cracks can be used to constrain both the velocity and prestress state associated with the ancient earthquake ruptures associated with their formation. Second, this model supports geological observations that coseismic off-fault tensile fracturing can occur even at seismogenic depths but requires narrow range of possible rupture velocity and prestress conditions (Figure 16). The formation and orientation of these dynamic tensile cracks also depends strongly on the velocity-weakening behavior $\left(\beta^{*}\right)$ of the rocks at the fault interface within the rupture tip. It should be noted that in our model, for the same prestress state, different rupture velocities may produce the same inclination angle of the microcracks depending on the combinations of fault strength, tensile strength of the surrounding material, and the velocity-weakening rate $\beta^{*}$. Therefore, correct implementation of the model necessitates the need to determine these parameters carefully. Currently, few data from direct experiments exist on rate-dependent behavior of rocks at seismogenic depths and strain rates as demonstrated in the discussion (section 6) of the estimation of $\beta^{*}$ for granodiorites in the Adamello batholith. Continued research on the frictional behavior of crustal rocks in the parameter space $\left(\dot{\delta}_{n}, \sigma_{n}\right)$ relevant to earthquake rupture propagation at seismogenic depths, within the context of the fracture mechanics-based model presented in this paper, will significantly add to our understanding of near-tip earthquake physics. It should also be noted that the current model does not explain the spacing or length of these microcracks. Further study of these parameters is needed to fully understand the mechanics of off-fault damage due to tensile fracture during earthquakes. Appropriate crack growth models taking into account crack tip interactions of immediate microcrack neighbors will be necessary to analyze spacing and length. Previous slip-weakening model formulations have also been successfully used to study off-fault tensile and Coulomb secondary failure. The results of our velocityweakening model make similar predictions regarding pseudotachylyte injection veins to calculations by $D i$ Toro et al. [2005b] using a slip-weakening pulse formulation. However, because frictional weakening is dependent on slip velocity and normal stress, results of the velocity-weakening and slip-weakening formulations are likely to diverge for different stress states. Experimental results show that a single velocity-weakening parameter, $\beta^{*}$, can successfully predict off-fault tensile failure for a variety of static prestress states suggesting that the velocity model formulation developed here is extremely versatile.

\section{Appendix A: Derivation of Traction Distributions in the Cohesive Zone}

[50] The stress distribution in the cohesive zone on the rupture faces can be obtained following the derivations of Samudrala et al. [2002]. The distributions of stress components $\sigma_{22}$ and $\sigma_{12}$ are given in equations (6) and (7) as boundary conditions. The derivation for the stress component $\sigma_{11}$ is summarized here.

[51] Samudrala et al. [2002] showed that

$$
G^{\prime \prime}\left(z=\eta_{1}+i \eta_{2}\right)=-\frac{\left(1-\alpha_{s}^{2}\right)}{2 \alpha_{s}} F^{\prime \prime}(z)
$$

Using this relation together with equation (4), we obtain the expression for stress component $\sigma_{11}$ on the rupture faces as

$$
\sigma_{11}\left(\eta_{1}, \eta_{2}=0\right)=2 \mu\left(\alpha_{l}^{2}-\alpha_{s}^{2}\right) \operatorname{Re}\left[F^{\prime \prime}\left(\eta_{1}\right)\right]+T
$$

where the function $F^{\prime \prime}$ is given by

$$
\begin{aligned}
F^{\prime \prime}(z)= & \frac{1}{\pi i} \frac{2 \alpha_{s}}{\mu R\left(v_{I I}\right)} \frac{1}{\sqrt{z}} \int_{-L}^{0} \frac{\tau(\xi / L)}{\sqrt{|\xi|}} d \xi \\
& +\frac{1}{\pi i} \frac{2 \alpha_{s}}{\mu R\left(v_{I I}\right)} \frac{1}{\sqrt{z}} \int_{-L}^{0} \frac{\sqrt{|\xi|} \tau(\xi / L)}{\xi-z} d \xi
\end{aligned}
$$


To determine $F^{\prime \prime}$ on the upper rupture face, $F^{\prime \prime+}\left(\eta_{1}\right)=$ $F^{\prime \prime}\left(\eta_{1}, \eta_{2} \rightarrow 0^{+}\right)$, we use Plemelj formulae together with equation (12) of Samudrala et al. [2002],

$$
i F^{\prime \prime}+\left(\eta_{1}\right)-(-i) F^{\prime \prime}-\left(\eta_{1}\right)=\frac{4 \alpha_{s}}{\mu R\left(v_{I I}\right)} \tau\left(\eta_{1} / L\right) \quad\left(-L<\eta_{1}<0\right),
$$

and obtain

$$
\begin{aligned}
F^{\prime \prime}+\left(\eta_{1}\right)= & -\frac{1}{\pi} \frac{2 \alpha_{s}}{\mu R\left(v_{I I}\right)} \frac{1}{\sqrt{\eta_{1}}} \mathrm{pv} \int_{-L}^{0} \frac{\tau(\xi / L)}{\sqrt{|\xi|}}\left(1+\frac{|\xi|}{\xi-\eta_{1}}\right) d \xi \\
& +\frac{2 \alpha_{s} \tau\left(\eta_{1} / L\right)}{\mu R\left(v_{I I}\right)} \frac{1}{i} \quad\left(-L<\eta_{1}<0\right)
\end{aligned}
$$

in the cohesive zone, where "pv" stands for Cauchy principal value.

[52] The stress component $\sigma_{11}^{+}$on the upper rupture face now can be expressed in terms of the shear traction $\tau$ as

$$
\begin{aligned}
\sigma_{11}^{+}\left(\eta_{1}\right)= & 2 \mu\left(\alpha_{l}^{2}-\alpha_{s}^{2}\right) \operatorname{Re}\left[F^{\prime \prime}+\left(\eta_{1}\right)\right]+T \\
= & -\frac{1}{\pi} \frac{4\left(\alpha_{l}^{2}-\alpha_{s}^{2}\right) \alpha_{s}}{R\left(v_{I I}\right)} \sqrt{\eta_{1}} \mathrm{pv} \int_{-L}^{0} \frac{\tau(\xi / L)}{\sqrt{|\xi|}\left(\xi-\eta_{1}\right)} d \xi+T \\
& \cdot\left(-L<\eta_{1}<0\right)
\end{aligned}
$$

Substituting equation (10) into the above equation, we obtain the normalized stress component $\sigma_{11}^{+}$on the upper rupture face as

$$
\begin{aligned}
\frac{\sigma_{11}^{+}}{\tau_{o}}\left(\frac{\eta_{1}}{L}\right)= & -\frac{1}{\pi} \frac{4\left(\alpha_{l}^{2}-\alpha_{s}^{2}\right) \alpha_{s}}{R\left(v_{I I}\right)} \sqrt{\frac{\eta_{1}}{L}}\left(\frac{-\eta_{1} / L}{1+\eta_{1} / L}\right)^{\gamma} \cos \pi \gamma \\
& \cdot \int_{0}^{1} \frac{(1-s) \gamma}{\sqrt{s}\left(1+s \eta_{1} / L\right)} d s+\frac{T}{\tau_{0}}\left(-1<\eta_{1} / L<0\right) .
\end{aligned}
$$

[53] Acknowledgments. This manuscript benefited from comments and suggestions by the Associate Editor and two anonymous reviewers. Experiments were supported by the U.S. Geological Survey (USGS), Department of Interior, under USGS award 08HQGR0010 to Pollard. Griffith also received support under National Science Foundation (NSF) grant OISE-0754258. Rosakis and Ngo were supported by U.S. Department of Energy grant DE-FG52-06NA 26209, NSF grant EAR-0711545, and Office of Naval Research Multidisciplinary Research Initiative (ONR MURI) grant N0014-06-1-0730.

\section{References}

Andrews, D. J. (1976), Rupture velocity of plane strain shear cracks, J. Geophys. Res., 81, 5679-5687, doi:10.1029/JB081i032p05679.

Archuleta, R. (1984), A faulting model for the 1979 Imperial Valley earthquake, J. Geophys. Res., 89, 4559-4585, doi:10.1029/JB089iB06p04559.

Arndt, J., T. Bartel, E. Scheuber, and F. Schilling (1997), Thermal and rheological properties of granodioritic rocks from the Central Andes, north Chile, Tectonophysics, 217, 75-88, doi:10.1016/S0040-1951(96) 00218-1.

Bass, J. D. (1995), Elasticity of minerals, glasses and melts, in Mineral Physics and Crystallography: A Handbook of Physical Constants, Ref. Shelf, vol. 2, edited by T. J. Ahrens, pp. 45-63, AGU, Washington, D. C., doi:10.1029/RF002p0045.

Beeler, N., T. E. Tullis, and D. L. Goldsby (2008), Constitutive relationships and physical basis of fault strength due to flash heating, J. Geophys. Res., 113, B01401, doi:10.1029/2007JB004988.

Ben-Zion, Y., and Z. Shi (2005), Dynamic rupture on a material interface with spontaneous generation of plastic strain in the bulk, Earth Planet. Sci. Lett., 236, 486-496, doi:10.1016/j.eps1.2005.03.025.

Ben-Zion, Y., Z. Peng, D. Okaya, L. Seeber, J. G. Armbruster, N. Ozer, A. J. Michael, S. Baris, and M. Aktar (2003), A shallow fault zone structure illuminated by trapped waves in the Karadere-Duzce branch of the
North Anatolian Fault, western Turkey, Geophys. J. Int., 152, 699-717, doi:10.1046/j.1365-246X.2003.01870.x.

Bhat, H. S., R. Dmowska, G. C. P. King, Y. Klinger, and J. R. Rice (2007), Off-fault damage patterns due to supershear ruptures with application to the $2001 M_{\mathrm{w}} 8.1$ Kokoxili (Kunlun) Tibet earthquake, J. Geophys. Res., 112, B06301, doi:10.1029/2006JB004425.

Biegel, R. L., C. G. Sammis, and A. J. Rosakis (2007), Interaction of a dynamic rupture on a fault plane with short frictionless fault branches, Pure Appl. Geophys., 164, 1881-1904, doi:10.1007/s00024-007-0251-2.

Biegel, R. L., H. S. Bhat, C. G. Sammis, and A. J. Rosakis (2010), The effect of asymmetric damage on dynamic shear rupture propagation I: No mismatch in bulk elasticity, Tectonophysics, 493, 254-262, doi:10.1016/j. tecto.2010.03.020.

Bieniawski, Z. T. (1984), Rock Mechanics Design in Mining and Tunneling, A. A. Balkema, Rotterdam, Netherlands.

Bouchon, M., and M. Vallée (2003), Observation of long supershear rupture during the magnitude 8.1 Kunlunshan earthquake, Science, 301, 824-826, doi:10.1126/science.1086832.

Bouchon, M., M. Bouin, H. Karabulut, M. N. Toksoz, M. Dietrich, and A. J. Rosakis (2001), How fast is rupture during an earthquake? New insights from the 1999 Turkey earthquake, Geophys. Res. Lett., 28, 2723-2726, doi:10.1029/2001GL013112

Broberg, K. B. (1995), Dynamic crack propagation in a layer, Int. J. Solids Struct., 32(6-7), 883-896, doi:10.1016/0020-7683(94)00166-T.

Byerlee, J. (1978), Friction of rocks, Pure Appl. Geophys., 116, 615-626, doi:10.1007/BF00876528.

Dalguer, L. A., K. Irikura, and J. D. Riera (2003), Simulation of tensile crack generation by three-dimensional dynamic shear rupture propagation during an earthquake, J. Geophys. Res., 108(B3), 2144, doi:10.1029/ 2001JB001738.

Di Toro, G., and G. Pennacchioni (2004), Superheated friction-induced melts in zoned pseudotachylytes within the Adamello tonalities (southern Italian Alps), J. Struct. Geol., 26, 1783-1801, doi:10.1016/j.jsg.2004. 03.001 .

Di Toro, G., S. Nielsen, and G. Pennacchioni (2005a), Rupture dynamics frozen in exhumed ancient faults, Nature, 436, 1009-1012, doi:10.1038 nature 03910 .

Di Toro, G., G. Pennacchioni, and G. Teza (2005b), Can pseudotachylytes be used to infer earthquake source parameters? An example of limitations in the study of exhumed faults, Tectonophysics, 402, 3-20, doi:10.1016/j. tecto. 2004.10.014.

Fialko, Y. (2004), Probing the mechanical properties of seismically active crust with space geodesy: Study of the coseismic deformation due to the $1992 M_{w}$ 7.3 Landers (southern California) earthquake, J. Geophys. Res., 109, B03307, doi:10.1029/2003JB002756.

Fialko, Y., L. Rivera, and H. Kanamori (2004), Estimate of differential stress in the upper crust from variations in topography and strike along the San Andreas fault, Geophys. J. Int., 158, 527-532, doi:10.1111/ j.1365-246X.2004.02511.x.

Freund, L. B. (1979), The mechanics of dynamic shear crack propagation, J. Geophys. Res., 84, 2199-2209, doi:10.1029/JB084iB05p02199.

Freund, L. B. (1990), Dynamic Fracture Mechanics, Cambridge Univ. Press, Cambridge, U. K., doi:10.1017/CBO9780511546761.

Freund, L. B., and Y. J. Lee (1990), Observations on high strain rate crackgrowth based on a strip yield model, Int. J. Fract., 42, 261-276, doi:10.1007/BF00013217.

Freund, L. B., and A. J. Rosakis (1992), The structure of the near-tip field during transient elastodynamic crack growth, J. Mech. Phys. Solids, 40, 699-719, doi:10.1016/0022-5096(92)80010-N.

Griffith, A. A. (1925), The theory of rupture, in Proceedings of the First International Congress for Applied Mechanics, edited by C. B. Biezeno and J. M. Burgers, pp. 55-63, Waltman, Delft, Netherlands.

Griffith, W. A., G. Di Toro, G. Pennacchioni, and D. D. Pollard (2008), Thin pseudotachylytes in faults of the Mt. Abbot Quadrangle, Sierra Nevada California: Physical constraints on seismic slip, J. Struct. Geol., 30, 1086-1094, doi:10.1016/j.jsg.2008.05.003.

Griffith, W. A., G. Di Toro, G. Pennacchioni, D. D. Pollard, and S. Nielsen (2009a), Static stress drop associated with brittle slip events on exhumed faults, J. Geophys. Res., 114, B02402, doi:10.1029/2008JB005879.

Griffith, W. A., A. J. Rosakis, D. D. Pollard, and C.-W. Ko (2009b), Dynamic rupture experiments elucidate tensile crack development during propagating earthquake ruptures, Geology, 37, 795-798, doi:10.1130/ G30064A.1.

Griffith, W. A., P. F. Sanz, and D. D. Pollard (2009c), Influence of outcrop scale fractures on the effective stiffness of fault damage zone rocks, Pure Appl. Geophys., 166, 1595-1627, doi:10.1007/s00024-009-0519-9. 
Griffith, W. A., S. Nielsen, G. Di Toro, and S. A. F. Smith (2010), Rough faults, distributed weakening, and off-fault deformation, J. Geophys. Res., 115, B08409, doi:10.1029/2009JB006925.

Heaton, T. H. (1990), Evidence for and implications of self-healing pulses of slip in earthquake rupture, Phys. Earth Planet. Inter., 64, 1-20, doi:10.1016/0031-9201(90)90002-F.

Hickman, S., and M. Zoback (2004), Stress orientations and magnitudes in the SAFOD pilot hole, Geophys. Res. Lett., 31, L15S12, doi:10.1029/ 2004GL020043

Inglis, C. E. (1913), Stresses in a plate due to the presence of cracks and sharp corners, Soc. Nav. Archit. Mar. Eng. Trans., 55, 219-230.

Kavaturu, M., A. Shukla, and A. J. Rosakis (1998), Intersonic crack propagation along interfaces: Experimental observations and analysis, J. Exp. Mech., 38, 218-225, doi:10.1007/BF02325746.

Kilgore, B. D., M. L. Blanpied, and J. H. Dieterich (1993), Velocitydependent friction of granite over a wide range of conditions, Geophys. Res. Lett., 20, 903-906, doi:10.1029/93GL00368.

Li, Y.-G., K. Aki, D. Adams, A. Hasemi, and W. H. K. Lee (1994), Seismic guided waves trapped in the fault zone of the Landers, California, earthquake of 1992, J. Geophys. Res., 99, 11,705-11,722, doi:10.1029/ 94JB00464.

Liu, C., and A. J. Rosakis (1994), On the higher order asymptotic analysis of a non-uniformly propagating dynamic crack along an arbitrary path, J. Elast., 35, 27-60, doi:10.1007/BF00115538.

Lu, X., N. Lapusta, and A. J. Rosakis (2007), Pulse and crack-like ruptures in experiments mimicking crustal earthquakes, Proc. Natl. Acad. Sci. U. S. A., 104(48), 18,931-18,936(PNAS), doi:10.1073/pnas.0704268104.

Lu, X., N. Lapusta, and A. J. Rosakis (2009), Analysis of supershear transition regimes in rupture experiments: The effect of nucleation conditions and friction parameters, Geophys. J. Int., 177, 717-732, doi:10.1111/ j.1365-246X.2009.04091.x

Marone, C. (1998), Laboratory-derived friction laws and their application to seismic faulting, Annu. Rev. Earth Planet. Sci., 26, 643-696, doi:10.1146/annurev.earth.26.1.643.

Martel, S. J. (1990), Formation of compound strike-slip fault zones, Mount Abbot quadrangle, California, J. Struct. Geol., 12, 869-882, doi:10.1016/ 0191-8141(90)90060-C

Martel, S. J., and D. D. Pollard (1989), Mechanics of slip and fracture along small faults and simple strike-slip fault zones in granitic rock, J. Geophys. Res., 94, 9417-9428, doi:10.1029/JB094iB07p09417.

Martel, S. J., D. D. Pollard, and P. Segall (1988), Development of simple strike-slip fault zones, Mount Abbot quadrangle, Sierra Nevada, California, Geol. Soc. Am. Bull., 100, 1451-1465, doi:10.1130/00167606(1988) $100<1451:$ DOSSSF $>2.3 . \mathrm{CO} ; 2$.

Mittempergher, S., L. Dallai, G. Di Toro, and G. Pennacchioni (2009), Origin of fluids in seismic faults from stable isotope study of pseudotachylytes, Geophys. Res. Abstr., 11, EGU2009-335-1.

Mutlu, O., and D. D. Pollard (2008), On the patterns of wing cracks along an outcrop scale flaw: A numerical modeling approach using complementarity, J. Geophys. Res., 113, B06403, doi:10.1029/2007JB005284.

Niemeijer, A., G. Di Toro, S. B. Nielsen, S. A. F. Smith, W. A. Griffith P. Scarlato, G. Romeo, G. Di Stefano, F. Di Felice, and S. Mariano (2009), A new state-of-the-art tool to investigate rock friction under extreme slip velocities and accelerations: SHIVA, Eos Trans. AGU, 90(52), Fall Meet. Suppl., Abstract T23C-1950.

Olsen, K. B., R. J. Madariaga, and R. J. Archuleta (1997), Threedimensional dynamic simulation of the 1992 Landers earthquake, Science, 278, 834-838, doi:10.1126/science.278.5339.834.

Orowan, E. (1949), Fracture and strength of solids, Rep. Prog. Phys., 12, 185-232, doi:10.1088/0034-4885/12/1/309.

Pennacchioni, G., G. Di Toro, P. Brack, L. Menegon, and I. M. Villa (2006), Brittle-ductile-brittle deformation during cooling of tonalite (Adamello, southern Italian Alps), Tectonophysics, 427, 171-197, doi:10.1016/j.tecto.2006.05.019.

Poliakov, A. N. B., R. Dmowska, and J. R. Rice (2002), Dynamic shear rupture interactions with fault bends and off-axis secondary faulting, J. Geophys. Res., 107(B11), 2295, doi:10.1029/2001JB000572.

Pollard, D. D., and P. Segall (1987), Theoretical displacements and stresses near fractures in rock: With applications to faults, joints, veins, dikes, and solution surfaces, in Fracture Mechanics of Rock, edited by B. K. Atkinson, pp. 277-348, Academic, London.

Reches, Z., and T. A. Dewers (2005), Gouge formation by dynamic pulverization during earthquake rupture, Earth Planet. Sci. Lett., 235, 361-374, doi:10.1016/j.epsl.2005.04.009.

Rice, J. R. (2006), Heating and weakening of faults during earthquake slip, J. Geophys. Res., 111, B05311, doi:10.1029/2005JB004006.

Rice, J. R., and A. Ruina (1983), Stability of steady frictional slipping, J. Appl. Mech, 50(2), 343-349. doi:10.1115/1.3167042.
Rice, J. R., C. G. Sammis, and R. Parsons (2005), Off-fault secondary failure induced by a dynamic slip-pulse, Bull. Seismol. Soc. Am., 95(1), 109-134, doi:10.1785/0120030166

Rosakis, A. J. (2002), Intersonic shear cracks and fault ruptures, Adv. Phys., 51, 1189-1257, doi:10.1080/00018730210122328.

Rosakis, A. J., O. Samudrala, and D. Coker (1999), Crack faster than shear wave speed, Science, 284, 1337-1340, doi:10.1126/science.284.5418.1337.

Rosakis, A. J., O. Samudrala, and D. Coker (2000), Intersonic shear crack growth along weak planes, Mater. Res. Innovations, 3, 236-243, doi: $10.1007 / \mathrm{s} 100190050009$

Rosakis, A. J., G. Lykotrafitis, K. Xia, and H. Kanamori (2007), Dynamic shear rupture in frictional interfaces: Speeds, directionality and modes, in Treatise in Geophysics, vol. 4, Earthquake Seismology, edited by H. Kanamori, pp. 153-192, Elsevier, Amsterdam.

Sagy, A., Z. Reches, and I. Roman (2001), Dynamic fracturing: Field and experimental observations, J. Struct. Geol., 23, 1223-1239, doi:10.1016/S0191-8141(00)00190-5

Sagy, A., Z. Reches, and J. Fineberg (2002), Dynamic fracture by large extraterrestrial impacts as the origin of shatter cones, Nature, 418 , 310-313, doi:10.1038/nature00903

Sammis, C. G., A. J. Rosakis, and H. S. Bhat (2009), Effects of off-fault damage on earthquake rupture propagation: Experimental studies, Pure Appl. Geophys., 166, 1629-1648, doi:10.1007/s00024-009-0512-3.

Samudrala, O., Y. Huang, and A. J. Rosakis (2002), Subsonic and intersonic shear rupture of weak planes with a velocity weakening cohesive zone, J. Geophys. Res., 107(B8), 2170, doi:10.1029/2001JB000460.

Scholz, C. H., and J. T. Engelder (1976), The role of asperity indentation and ploughing in rock friction: I. Asperity creep and stick slip, Int. J. Rock Mech. Min. Sci., 12, 149-154.

Sibson, R. H. (1974), Frictional constraints on thrust, wrench, and normal faults, Nature, 249, 542-544, doi:10.1038/249542a0

Sibson, R. H., and V. G. Toy (2006), The habit of fault-generated pseudotachylyte: Presence vs. absence of friction-melt, in Earthquakes: Radiated Energy and the Physics of Faulting, Geophys. Monogr. Ser., vol. 170, edited by R. Abercrombie et al., pp. 153-166, AGU, Washington, D. C.

Swanson, M. T. (1988), Pseudotachylyte-bearing strike-slip duplex structures in the Fort Foster Brittle Zone, S. Maine, J. Struct. Geol., 10, 813-828, doi:10.1016/0191-8141(88)90097-1.

Townend, J., and M. Zoback (2000), How faulting keeps the crust strong, Geology, 28, 399-402, doi:10.1130/0091-7613(2000)28<399:HFKTCS> $2.0 . \mathrm{CO} \cdot 2$

Tribe, I. R., and R. S. D'Lemos (1996), Significance of a hiatus in downtemperature fabric development within syn-tectonic quartz diorite complexes, Channel Islands, UK, J. Geol. Soc., 153, 127-138, doi:10.1144/ gsjgs. 153.1.0127

Tsutsumi, A., and T. Shimamoto (1997), High-velocity frictional properties of gabbro, Geophys. Res. Lett., 24, 699-702, doi:10.1029/97GL00503. Tullis, T., and J. D. Weeks (1986), Constitutive behavior and stability of frictional sliding of granite, Pure Appl. Geophys., 124, 383-414, doi:10.1007/BF00877209.

Tullis, T. E., et al. (2007), Group report: Rheology of fault rocks and their surroundings, in Tectonic Faults: Agents of Change on a Dynamic Earth, edited by M. R. Handy and G. Hirth, N. Hovius, pp. 183-204, MIT Press, Cambridge, Mass.

Ulrich, T. J., K. R. McCall, and R. A. Guyer (2002), Determination of elastic moduli of rock samples using resonant ultrasound spectroscopy, J. Acoust. Soc. Am., 111, 1667-1674, doi:10.1121/1.1463447.

Vernon, R. H. (2004), A Practical Guide to Rock Microstructure, Cambridge Univ. Press, Cambridge, U. K

Willemse, E. J. M., and D. D. Pollard (1998), On the orientation and patterns of wing cracks and solution surfaces at the tips of a sliding flaw or fault, J. Geophys. Res., 103, 2427-2438, doi:10.1029/97JB01587.

Xia, K., A. J. Rosakis, and H. Kanamori (2004), Laboratory earthquakes: The sub-Rayleigh to supershear rupture transition, Science, 303, 1859 1861, doi:10.1126/science.1094022.

Xia, K., A. J. Rosakis, H. Kanamori, and J. R. Rice (2005), Laboratory earthquakes along inhomogeneous faults: Directionality and supershear, Science, 308, 681-684

Xu, X., G. Yu, Y. Klinger, P. Tapponnier, and J. Van Der Woerd (2006), Reevaluation of surface rupture parameters and faulting segmentation of the 2001 Kunlunshan earthquake $\left(M_{w} 7.8\right)$, northern Tibetan Plateau, China, J. Geophys. Res., 111, B05316, doi:10.1029/2004JB003488.

Yamashita, T. (2000), 2000, Generation of microcracks by dynamic shear rupture and its effects on rupture growth and elastic wave radiation, Geophys. J. Int., 143, 395-406, doi:10.1046/j.1365-246X.2000.01238.x. Yoffe, E. H. (1951), The moving Griffith crack, Philos. Mag., 42, 739-750

Yuan, F., and V. Prakash (2008), Use of a modified torsional Kolsky bar to study frictional slip resistance in rock-analogue materials at coseismic 
slip rates, Int. J. Solids Struct., 45, 4247-4263, doi:10.1016/j.ijsolstr. 2008.03.012.

Yuan, F., V. Prakash, and T. Tullis (2011), Origin of pulverized rocks during earthquake fault rupture, J. Geophys. Res., 116, B06309, doi:10.1029/ 2010JB007721.

Zheng, G., and J. R. Rice (1998), Conditions under which velocityweakening friction allows a self-healing versus a cracklike mode of rupture, Bull. Seismol. Soc. Am., 88, 1466-1483.

Zoback, M. D., and H.-P. Harjes (1997), Injection-induced earthquakes and crustal stress at $9 \mathrm{~km}$ depth at the KTB deep drilling site, Germany, J. Geophys. Res., 102, 18,477-18,491, doi:10.1029/96JB02814.
Zoback, M. D., et al. (1987), New evidence on the state of stress of the San Andreas fault system, Science, 238, 1105-1111, doi:10.1126/ science.238.4830.1105

W. A. Griffith, Department of Geology and Environmental Science, University of Akron, Akron, OH 44325-4101, USA. (wag8@uakron.edu) Y. Huang, Department of Mechanical Engineering, Northwestern University, 2145 Sheridan Rd., Evanston, IL 60208, USA.

D. Ngo and A. Rosakis, Graduate Aerospace Laboratories, California Institute of Technology, Pasadena, CA 91125, USA.

D. Pollard, Department of Geological and Environmental Sciences, Stanford University, 450 Serra Mall, Bldg. 320, Stanford, CA 943052115 , USA 